\title{
Chemical Structure and Reactivity by means of Quantum Chemical Topology Analysis
}

Juan Andrés*, Lourdes Gracia, Patricio González-Navarrete, and Vicent S. Safont

Departament de Química Física i Analítica, Universitat Jaume I, Avda. Sos Baynat s/n, 12071 Castelló, Spain

*Corresponding author: andres@qfa.uji.es 


\begin{abstract}
Chemical structure and bonding are key features and concepts in chemical systems which are used in deriving structure-property relationships, and hence in predicting physical and chemical properties of compounds. Even though the contemporary high standards in determination, using both theoretical methods and experimental techniques, questions of chemical bonds as well as their evolution along a reaction pathway are still highly controversial. This paper presents a working methodology to determine the structure and chemical reactivity based on the quantum chemical topology analysis. QTAIM and ELF frameworks, based on the topological analysis of the electron density and the electron localization function, respectively, have been used. We have selected two examples studied by the present approach, to show its potential: (i) QTAIM study on the $\alpha \mathrm{Ag}_{2} \mathrm{WO}_{4}$, for the simulation of $\mathrm{Ag}$ nucleation and formation on $\alpha \mathrm{Ag}_{2} \mathrm{WO}_{4}$ provoked in this crystal by the electron-beam irradiation. (ii) An ELF and Thom's catastrophe theory study for the reaction pathway associated with the decomposition of stable planar hypercoordinate carbon species, $\mathrm{CN}_{3} \mathrm{Mg}_{3}{ }^{+}$.
\end{abstract}


Chemistry is the science of substances: their structure, their properties, and the reactions that change them into other substances, as Linus Pauling wrote [1]. The understanding of formation and breaking of chemical bonds of any molecule forms the basis of molecular reactivity, and the reach of this mechanistic achievement depends on knowing the nature of the chemical bonds in the molecules. As very recently Ruedenberg et al. quoted [2] : "Covalent bond formation is a fundamental chemical reaction. Yet, its physical origin has remained obscure to most chemists. Most general chemistry textbooks either avoid the subject or advance incorrect explanations".

The "classical" concepts of bonding analysis, based on molecular orbitals (MO) [3], valence bond theory (VB) [4,5], MO-related natural bond orbitals (NBO) approach [6], Woodward-Hoffmann rules [7], Fukui's frontier molecular orbital (FMO) theory [8], or Marcus theory [9] have enormously contributed to the current understanding of fundamental chemical reactions. However, they are seriously challenged because their origin and nature are still subject to much discussion and scientific inquiry [10]. As Coulson insists. "I believe that chemical bond is not so simple as some people seem to think" [11]. 


\section{Chemical structure (bond) and reactivity}

The concept of chemical bond (CB) has been deeply anchored in the mind of chemists and in consequence it has been used to rationalize important characteristics of many chemical compounds such as the structure, stability, spectroscopy, and chemical reactivity. Generally speaking, $\mathrm{CB}$ is a matter of favorable arrangement of nuclei and electrons in a molecule as a complex building. Thus, visualizing chemical bonds in molecules could be considered the holy grail of chemical community to understand at the most fundamental level how atoms bond to form molecules [12-16]. Despite nearly two centuries of its introduction, "what is a chemical bond?" still remains a critical question for chemical community because of the lack of a unique definition of the term as well as unclear understanding of their physical nature [17]. This fact has generated a large and strong discussion on this research field while different methods for their validation are still under development [18-42]. As it was remarked by Jacobsen [43]: "Note that the nature of the chemical bond has changed since Pauling published the last edition of his authoritative and defining monograph [44], but the approach to the subject has evolved, and it now seems that the chemical bond is better described as a noumenon rather than as a phenomenon" $[45,46]$.

The essence of the chemical reactivity is to determine the evolution of the CBs in a given chemical process, i.e. how the making and breaking processes are taking place as the reaction proceeds. But, it is one of the most challenging problem due to the complexity of the electronic structure in the transient regime of forming or breaking CBs. Unfortunately, there is no physical observable corresponding to the $\mathrm{CB}$ and their rearrangement along a given chemical reaction; such concepts therefore cannot be unambiguously defined in pure quantum theory. However, qualitative concepts are of essential importance for practical chemistry. For that reason, a large number of competing techniques have been developed for extracting them from quantum chemical calculations.

From a quantum perspective, molecules are defined by a full specification of quantum numbers for the correlated electron and nuclear motion. Determining molecular structure and changes that occur during a chemical reaction, including the structures of transition states (TSs) are critical challenges in chemical physics. In the course of a chemical reaction, the making and the breaking of bonds is regulated by the correlated motion of electrons and nuclei. To gain a complete understanding of a 
chemical reaction it is necessary to determine the structural changes that occur to the reacting molecules. In this sense, chemical reactions are often described in terms of the motion of atoms of the reacting molecules on a potential energy surface (PES) to form the product molecules $[47,48]$. Theoretical studies about reaction mechanisms are usually limited to the determination of the energetic paths that connect reactants, transition states, and products on these PESs [49,50], while chemical concepts, such as the reaction rate and the reaction barrier have been calculated by means of transition state theory [51]. In this sense, Truhlar et al. have presented an overview of the current status of the theory of chemical kinetics and mechanisms for complex processes [52]. These procedures are hugely successful and they can be considered as an energeticsdriven approach to computational theoretical and chemistry. Then, this research field constitutes a central application of quantum chemistry to the study of stationary points of PESs [53] and the pathways connecting them. The shape of an adiabatic PES is conventionally regarded as a function of the nuclear skeleton, ignoring the wealth of information that can be provided by the total electronic charge density distribution $\rho(r)$.

The driving force for the nuclear motion is the potential, which arises from electronic motion. Chemical processes are determined by nuclear motions, which occur on timescales reaching into the domain of femtosecond ( $1 \mathrm{fs}=10^{-15} \mathrm{~s}$ ) [54], while electronic motion can occur on much faster, attosecond timescales $\left(1\right.$ as $\left.=10^{-18} \mathrm{~s}\right)$. From an experimental point of view, recent progress of techniques that, similar to ultrafast electron diffraction [55], or x-ray diffraction [56], have the potential to be taken to the time domain and follow chemical reactions on their natural time scale using ultrafast spectroscopy to gain a detailed understanding of chemical reactions (including their transition structures, TSs). It promises to be a revolutionary way to increase reaction efficiencies and enhance the reaction products. Crossed molecular beam experiments at femto-scale [57] to atto-scale [58,59] use ultrafast pulsed lasers which permit the monitoring of the reacting molecular species on a sub-picosecond scale; then, reaction mechanisms can then be inferred from the details of the dynamics as the reaction proceeds from reactants to products. In addition, in the last few years, it has become possible to image chemical reactivity at the single-molecule and-particle level with fluorescence microscopy; however in order to image a chemical process, it needs to be associated with a change in fluorescent output that is detectable. This innovative research line has been reviewed by Blum and Cordes [60,61]. 


\section{Topological analysis}

Following the Hohenberg-Kohn theorem (HKT) [62] to represent and describe molecules and their corresponding chemical reactivity, the electron density corresponds to an appropriate choice because it is a local function defined within the exact many body theory, and it is also an experimentally accessible scalar field. As Martín-Pendás et al. [63] remark: "The best known approach is based on choosing the electron density, $\rho(\mathrm{r})$, as basic variable. This is the simplest invariant scalar that can be constructed from orbitals, and the joint use of the theorems of Hohenberg and Kohn [62] and Mezey [64] guarantees that such a scalar must carry chemical information both globally and locally." The global point of view has crystallized in what we know today as conceptual density functional theory [65], which has provided a sound physical foundation to electronegativity and electronegativity equalization, frontier orbital theory, etc. The local image, in turn, evolved independently, giving rise to topological theories of the chemical bond [66]. These powerful approaches work in synergy with the relief that a theory based on an experimentally available magnitude [67] incites in non-theoreticians.

The topological theory of molecular structure derives part of its validity from HKT, which posits that all ground-state molecular properties are a consequence of the charge density, a scalar field denoted here as $\rho(\mathrm{r})$ [62]. HKT guarantees that all the molecular information is encoded in the electron density, however to obtain a physical description of chemical systems, additional postulates area mandatory for extracting observable information in terms of atomic contributions [68]. In this context, the seminal works of Collard and Hall [69], Johnson [70], and Smith [71] to form a topological theory of molecular structure need to be cited. For a distribution of electronic charge associated with a nuclear configuration $\mathrm{X}$ the topological properties can be condensed into the number of different types of critical points of $\mathrm{q}(\mathrm{r}, \mathrm{X})$, that is, where the associated gradient vector $\Delta(\mathrm{r}, \mathrm{X})$ vanishes. In seventies, Bader's brilliant research program eventually established topological analysis of charge density as one of the most effective tools of modern computational chemistry [72-74]. The mathematical foundations as well as the available computational results were reviewed comprehensively [75-77].

In particular, the works of Richard F. W. Bader [66,75-79] provide precise mathematical definitions for $\mathrm{CB}$ and molecular structure and numerous studies were conducted in order to connect this approach with traditional concepts in chemistry [80]. 
As Professor Gatti [81] writes: "Quantum theory of atoms in molecules (QTAIM) uses the total electron density as the information from which to (re)formulate chemical concepts [66]. It provides a bridge between chemistry and quantum mechanics and shows that there is no need to invoke any arbitrary reference densities since all chemistry is already hidden in $\not$ r). QTAIM goes far beyond a simple topological study of a scalar field. It rather provides a full consistent quantum mechanical framework for the definition of the atoms or group of atoms in a molecule or crystal and for the treatment of the mechanics of their interaction". QTAIM starts from a particular division of real space into atomic basins. Given the appropriate operator density, any quantum mechanical observable can be integrated within the atomic basins, giving rise to the partition of properties into additive atomic contributions. The QTAIM features, such as the bounded atoms separated by the zero flux surfaces of the gradient of $\rho$ r), the critical points and the lines of maximum density between nuclei (the bond path) [82] yield a crystal structure description at the level of the bonding details [83]. In the majority of cases, bond paths and associated bond critical points occur between pairs of atoms that could be typically associated through chemical bonds and molecular interactions. Otero de la Roza and Luaña [84] have discussed the rigorous characterization of the electron density Laplacian of crystals in terms of its topological properties, as well as these authors have also presented a program for real-space analysis of quantum chemical interactions in solids [85]. Very recently, Shahbazian and Goli [86-88] have reviewed the QTAIM framework, providing some computational examples with particular emphasis on origins and applications, while Martín-Pendás et al. [89] have proved that QTAIM is a versatile tool to be applied to molecules in their electronic excited states, expanding the knowledge that the molecular orbital framework provides about electronic rearrangements.

In this context, the electronic structure of a molecule is described in real space terms using topological analysis. Beyond the well-known approach of the QTAIM, which relies on the properties of the electron density $\rho(r)$ when atoms interact, topological analysis of different scalar functions can be employed, such as the electron localization function (ELF) method [90-93]. Originally, ELF can be developed based on the conditional pair density [90] or can be derived from the kinetic energy density [94]. In the latter context, ELF is seen as the scaled difference between the positive kinetic energy density and the von Weizsäcker term [95], whereby the scaling function is the 
kinetic energy density of the homogeneous electron gas (Thomas-Fermi term) [96, 97]. In addition, other topological analysis of scalar functions have been also developed such as the source function [98], the momentum density [99], the electron pair density [100], the nuclear potential energy field [101], the virial field [102], the Laplacian of charge density [66,103-105], and the electron localizability indicator [106]. Da Silva and Corminboeuf [107] have introduced the density overlap regions indicator as a scalar field, which reveals both covalent and non-covalent interactions in the same value range and it has been exploited to visualize and quantify the concept of electronic compactness in supramolecular chemistry. In fact, topological analysis of various scalar fields, different to electron density, is now used in computational chemistry, such as the scalar field derived from the molecular electrostatic potential;[108] even the mathematical framework of topological analysis has been applied by Mezey on the study of potential energy hypersurfaces [109, 110].

In recent years, weak intermolecular interactions, involving van der Waals interactions, hydrogen bonds, halogen bonds and both attractive and repulsive steric interactions, have attracted considerable interest due to the fact that non covalent interactions (NCIs) play a central role in many areas of science, ranging from biochemistry to condensed matter [111-119]. Recently, Yang et al. [120-122] have proposed the reduced density gradients as a new scalar function based on the electron density $\rho(r)$ and its derivatives to map and analyze noncovalent interactions, identifying interactions in a chemical system, whereas the interest in studying simultaneously strong and weak interactions has led to applications of combined ELF/NCI analysis [123-125]. Very recently, this method has been extended and applied for plotting and analysis of NCIs to periodic (solid-state) electron densities [126], whereas a combined QTAIM and NCI analysis in solids has shown to provide a deeper insight into the nature of interactions in solids [127]. Also, this combination has been extended to study complex enzymatic reaction paths involving large biological systems treated at the QM/MM level [124, 128].

All these methods have been widely generalized to develop the so-called Quantum Chemical Topology (QCT) [129, 130]. QCT has been successfully employed for the analysis of chemical bond as well as to provide a further understanding of the chemical reactivity [131-138]. Likewise, Nasertayoob and Shahbazian [68] have presented an account on the mathematical foundations of the topological analysis of the 
electronic charge densities while Martín-Pendás et al. have presented an outlook on the use of quantum chemical topology techniques in crystallography [63].

The pictures of a molecule as drawn by the QTAIM and ELF analysis are complementary. Thus, the QTAIM analysis is based on the topology of the electron density $\rho(r)$, whereas the ELF analysis is based on the topology of the electron localization function using the conditional probability for the same spin pairs which is closely related to the local excess of kinetic energy due to the Pauli repulsion $[90,139]$. With QTAIM 3D, space of a molecule is partitioned into disjoint atomic basins, while with ELF the space is partitioned into 'localization basins' such as core basins, lone pair basins and bonding regions [139-145]. The QTAIM analysis provides the atomic basin population (an indicator of the net charge transfer) [142, 144, 145], the Laplacian value of the electron density, and the local energy density at the Bond critical point (BCP) [78, 142-149]. On the other hand, in the ELF analysis, the populations of the various basins give rise to a statistical analysis of the bonds, such as, bonding or non-bonding, bond order and bond polarity [135, 140-145,150,151].

\section{CatastropheTheory}

According to the HKT, all the molecular information is encoded in the electron density; nevertheless a physical description of chemical systems requires additional postulates for extracting observable information in terms of atomic contributions. Thus, the QTAIM introduced by Bader provides a quantum topological partitioning of the molecular space into chemically transferable molecular fragments for which the energy and all other measurable properties can be precisely defined [79]. In this way, the introduction of chemical concepts such as bond path enables the description of the evolution of the electronic structure along a reaction path and therefore reaction mechanisms can be studied from the redistribution of the electron density along the reaction path connecting the stationary points. Following the evolution of the electron density for a given chemical process Bader and co-workers pioneered the study of the structural change based on the electron density using Thom's theory of elementary catastrophes (CT) [66, 152]. However, the applicability of QTAIM to the study of reaction mechanisms was found to be limited in intramolecular processes because there are no topological changes in the charge density gradient field when a diatom 
dissociates. Thus, to further increase the applicability of the Thom's CT in chemical systems Silvi et al. [153] have developed the Bonding Evolution Theory (BET) as a generalization of Bader's work and to other scalar fields as ELF [153, 154]. A number of reaction types have been investigated using BET including reactions of cycloaddition [155,156], cyclization [157-159], electron transfer [160], inversion substitution [161], electronic fluxes during Diels-Alder reactions [156], involving metal compounds [162165] and inorganic reactions involving Mo complexes [166, 167] while MoralesBayuelo has analyzed the electronic reorganization in the thermal isomerization reaction of trans-3,4-dimethylcyclobutene [168]. Nizovtsev [169] has also studied the activation of $\mathrm{C}-\mathrm{H}$ bond in $\mathrm{CH}_{4}$ by $\mathrm{Pd}$ atom as well as electronic rearrangements during the Inversion of Lead Phthalocyanine [170] from a BET perspective to establish electron density redistribution in the course of structural rearrangements. Different examples where BET has been successfully applied to rationalize chemical reactivity have been reviewed comprehensively $[155,158,171]$.

On the other hand, it is important to remark that an important feature of BET is the ability to observe the flow of the electron density as the reaction proceeds, that is, BET gives access to the natural time scale of the chemical process. So, a recent study [172] of the degenerate Cope rearrangement of semibullvalene has shown good agreement with those results where time-dependent quantum simulations have been performed $[173,174]$. Thus, BET is capable to adequately predict the order, direction, and synchronicity of electron fluxes, providing rather valuable information when studying reaction mechanisms at elementary level.

On the other hand, Silvi et al. [123] have developed a cross ELF/NCI analysis to offer an alternative look of chemical mechanisms for prototypical organic reactions, while we have combined QTAIM and NCI index to describe the molecular mechanism for the $\mathrm{NH}_{3}+\mathrm{LiH} \rightarrow \mathrm{LiNH}_{2}+\mathrm{H}_{2}$ reaction [125]. In this study we have performed for the first time the topological analysis of the NCI taking account not only its sinks but also the saddle points for the construction of bifurcation trees. In addition we have shown that the NCI analysis can be considered as a global approach to QTAIM adding the following features: (i) changes in the NCI are not catastrophic, (ii) more interactions can be found, (iii) foresee interactions: the soft profile of NCI enables to predict the appearance of density critical points and (iv) characterization of delocalized interactions: the use of surfaces beyond critical points enables to identify delocalized interactions, such as the ones involved in TSs. 
Alternatively, Domingo et al. have analyzed the changes and evolution of ELF topology along the reaction pathways, avoiding the use of $\mathrm{CT}$, to describe a wide range of organic reactions such the $[5+2] v s .[4+2]$ cyclization mediated by Lewis acid in the quinone system [175], ionic Diels-Alder reactions [176], hetero Diels-Alder reactions [177], cycloaddition reactions [178], non-polar, polar and ionic organic reactions involving the participation of $\mathrm{C}=\mathrm{C}$ double bonds [179], Friedel-Crafts reactions [175], and $\mathrm{C}-\mathrm{C}$ bond formation in organic reactions involving cationic species [180]. In addition, Gérard and Chatigner [181] have studied the electronic displacements along the reaction path for the $[4+2] /[3+2]$ cycloadditions of 3 nitroindole with substituted alkenes by means of the topological analysis of ELF while Dobado et al. [182] have analyzed the electronic structure along the progress of the N, $\mathrm{P}$, and As Ylides and Aza- and Arsa-Wittig reactions through electron density with QTAIM and ELF. Morales-Bayuelo [168] has presented a topological analysis of the ELF along the most favorable outward pathway to characterize the electronic reorganization in the thermal isomerization reaction of trans-3,4-dimethylcyclobutene. Vallejos et al. [183] have analyzed the effect of the nature of the boron moiety upon the reactivity and the selectivity of a series of vinylboron compounds in the Diels-Alder reaction with cyclopentadiene by means of DFT methods and the QTAIM approach.

The seminal works of Martín-Pendás et al. present the application of the Bader's topological analysis and the Thom's theory in ionic crystals [184-186]. Later, Gibbs et al. [187-189] applied Bader's theory to characterize the high-pressure silica polymorphs as function of the nature of Si-O bond. It is well known that the compression of a solid induced by an increase of external pressure alleviates the electron-electron repulsion, so that the electrons will leave their bonding configuration and will populate the interstitial regions [190, 191]. Silvi et al. [192] have analyzed bonding changes along solid-solid phase transitions using ELF approach, and very recently Recio et al. [193] have analyzed by means of first principles calculations and topological analysis of ELF the $\alpha$-Cristobalite to Stishovite Transition path in $\mathrm{SiO}_{2}$. Different authors, such as Prencipe and Nestola [194], and Merli et al. [195-197], employ the Bader's topological analysis of the electron density, coupled with Thom's catastrophe theory, which has been used to characterize the pressure-induced transformations in mineral phases. On the other hand, Merliet al. [195] have emphasized the relation among the topological features of the electron density distribution, the structural stability of a molecular system and the breaking/formation of chemical bonds. Very recently, Vegas et al. [198] have carried 
out a topological analysis of ELF of the $\left(\mathrm{H}_{3} \mathrm{C}\right)_{3}$-Si-O-Si- $\left(\mathrm{CH}_{3}\right)_{3}$, molecule, as a model of the so-called ionic solids, such as in the skeletons of aluminate and silicate polyanions, while Kozlova et al.[199] have studied the evolution of chemical bonding and electron density rearrangements during $\mathrm{D}_{3 \mathrm{~h}} \rightarrow \mathrm{D}_{3 \mathrm{~d}}$ reaction in monolayered $\mathrm{TiS}_{2}$ by means of QTAIM and ELF procedures.

\section{Working examples}

In this study we present a working methodology to determine the structure and chemical reactivity based on the QCT analysis. QTAIM and ELF frameworks, based on the topological analysis of the electron density and the electron localization function, respectively, have been used. We have selected two examples studied by the present approach, to enhance its potential: (i) QTAIM study on the $\alpha \mathrm{Ag}_{2} \mathrm{WO}_{4}$, for the simulation of $\mathrm{Ag}$ nucleation and formation on $\alpha \mathrm{Ag}_{2} \mathrm{WO}_{4}$ provoked in this crystal by the electron-beam irradiation. (ii) An ELF and Thom's catastrophe theory study for the reaction pathway associated with the decomposition of stable planar hypercoordinate carbon species, $\mathrm{CN}_{3} \mathrm{Mg}_{3}{ }^{+}$.

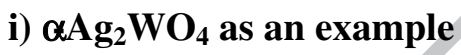

The motivation for our investigation essentially arises from the recent discovery of real-time in situ nucleation and growth of $\mathrm{Ag}$ filaments on $\alpha \mathrm{Ag}_{2} \mathrm{WO}_{4}$ crystals driven by an accelerated electron beam from an electronic microscope under high vacuum [200]. This is the first example of such studies in scientific literature which has become a trending topic in current research because it is a novel example of dynamic single crystals where electron irradiation induces macroscopic motility and represent not only a visually appealing demonstration of their potential for bactericide and photoluminescent applications [201, 202], but it also provides a unique opportunity to explore the mechanistic link between collective atomic processes and their consequences at a macroscopic level. This phenomenon has an electron-driven nature and the key difference in our approach is the use of an electron beam of TEM for growing Ag nanoparticles rather than for optical or electromagnetic erasing as it is the case in the plasmon effect. Not content with merely making these observations, we want to know the driving force and origin of this phenomenon. 
Because the formation of metallic $\mathrm{Ag}$ after the electron irradiation of $\alpha \mathrm{Ag}_{2} \mathrm{WO}_{4}$ is a quantum phenomenon, we performed quantum mechanical calculations to understand the structural and electronic modifications of $\alpha \mathrm{Ag}_{2} \mathrm{WO}_{4}$ that were observed experimentally [203]. In the calculations, electrons were introduced one by one up to ten in the orthorhombic unit cell of $\alpha \mathrm{Ag}_{2} \mathrm{WO}_{4}$ and a distribution of these extra electrons takes place by means of a simultaneously geometry optimization on both the lattice parameters and the atomic positions. First-principles total-energy calculations were carried out within the periodic DFT framework using the VASP program [204, 205]. The Kohn-Sham equations have been solved by means of the Perdew, Burke, and Ernzerhof exchange-correlation functional, and the electron-ion interaction described by the projector-augmented-wave pseudopotentials [206, 207]. Due to the well-known limitations of standard DFT in describing the electronic structure of "stronglycorrelated" compounds, a correction to the PBE wavefunctions are adopted (PBE+U) with the inclusion of a repulsive on-site Coulomb interaction (U) following the recipe of Dudarev et al. [208]. The value of the Hubbard parameter was tested, and a value of $U=$ $6 \mathrm{eV}$ for the $\mathrm{Ag}$ element was used to take into account orbital dependence (applied to the $d$ states of silver) of the Coulomb and exchange interactions. The plane-wave expansion was truncated at a cut-off energy of $400 \mathrm{eV}$ and the Brillouin zones have been sampled through Monkhorst-Pack special $k$-points grids that assure geometrical and energetic convergence for the $\mathrm{Ag}_{2} \mathrm{WO}_{4}$ structures considered in this work.

A graphical representation of $\alpha \mathrm{Ag}_{2} \mathrm{WO}_{4}$ using polyhedra is presented in Fig. 1 to show $\left[\mathrm{WO}_{6}\right]$ and $\left[\mathrm{AgO}_{\mathrm{x}}\right](\mathrm{x}=2,4,6$ and 7$)$ as the building blocks of this material, generating three different packing zones well delimited, core, shell1 and shell2.

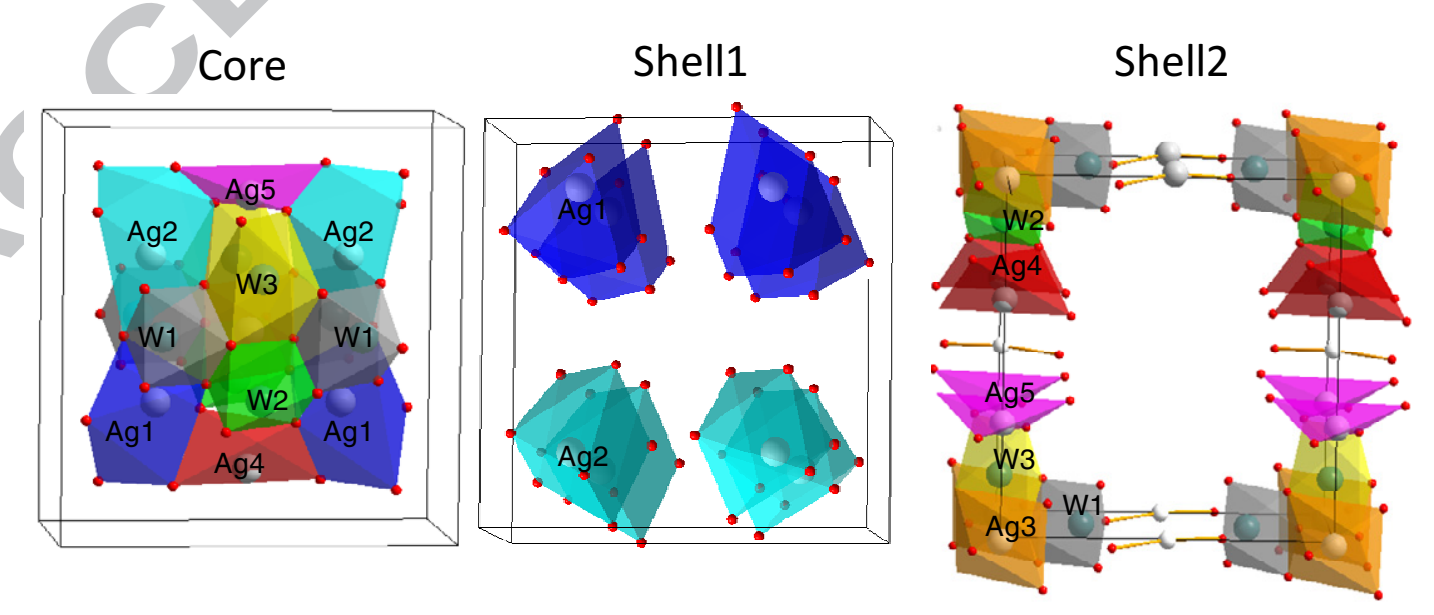


Figure 1. Bulk structure of $\alpha-\mathrm{Ag}_{2} \mathrm{WO}_{4}$ in terms of its constituent polyhedra, $\mathrm{WO}_{6}$ and $\mathrm{AgO}_{\mathrm{x}}(\mathrm{x}=2,4,6$, and 7), identifying three different packing zones.

The change of lattice constants $(a, b$, and $c)$ as a function of the number of added electrons are presented in Fig. 2.

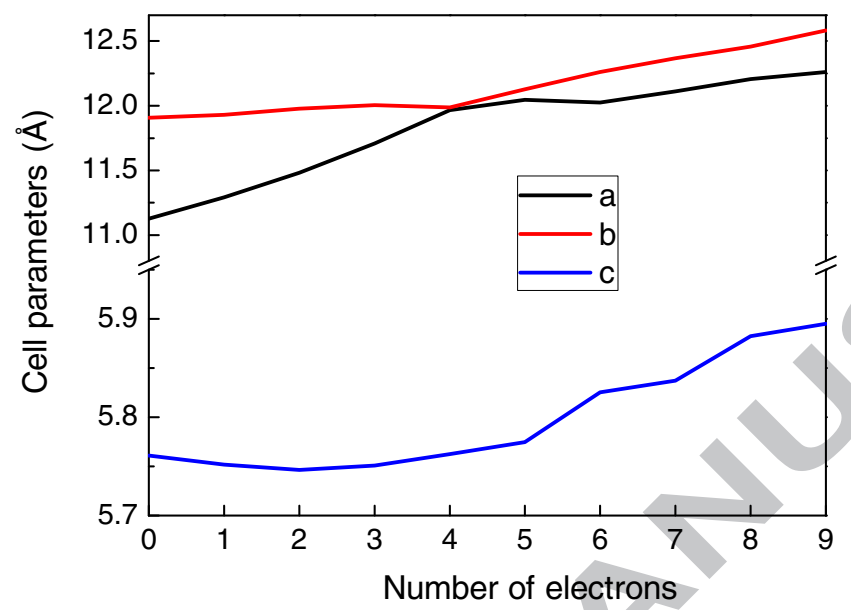

Figure 2. Variation of cell parameters as a function of the number of electrons added.

Table 1 presents the calculated values of the surface energy for (001), (100), (010), (011), (101) and (110) facets of $\alpha-\mathrm{Ag}_{2} \mathrm{WO}_{4}$. The surface (100) is the most stable facet, with the higher percentage of the relaxing process. If charged $\alpha-\mathrm{Ag}_{2} \mathrm{WO}_{4}$ structure is focused on the plane (100) compared to the equilibrium geometry, it can be seen an approaching of Ag4 and Ag5 centers (from $4.0 \AA$ to $3.26 \AA$ ) when the system is charged in the vicinity of $\mathrm{Ag} 6$ atoms. In addition, Ag6-O distance increases from $2.34 \AA$ to 2.54 $\AA$ showing that this situation favors an accumulation of Ag atoms along the most stable (100) surface. Therefore, the DFT calculations indicate that the absorption of electrons leads to the disordered structure that facilitates Ag nucleation.

Table 1. Number of $\mathrm{Ag}_{2} \mathrm{WO}_{4}$ units, area, surface energy and the relaxing percentage for (100), (001), (010), (011), (101) and (110) surfaces of $\alpha-\mathrm{Ag}_{2} \mathrm{WO}_{4}$. All surfaces are Oterminated.

\begin{tabular}{ccccc}
\hline & $\mathrm{n}$ & Area $\left(\mathrm{m}^{2}\right)$ & $\mathrm{E}_{\text {surf }}\left(\mathrm{J} \cdot \mathrm{m}^{-2}\right)$ & $\operatorname{Relax}(\%)$ \\
\hline$[100]$ & 8 & 71.9 & 0.11 & 87.1 \\
{$[001]$} & 12 & 137.3 & 0.61 & 57.4
\end{tabular}




\begin{tabular}{lcccc}
{$[010]$} & 8 & 64.8 & 1.68 & 56.2 \\
{$[011]$} & 10 & 151.8 & 2.01 & 24.4 \\
{$[101]$} & 9 & 154.9 & 1.60 & 37.7 \\
{$[110]$} & 10 & 96.8 & 1.58 & 38.3 \\
\hline
\end{tabular}

In Table 2, the values of the bond distances of $\mathrm{Ag}-\mathrm{O}$ and $\mathrm{W}-\mathrm{O}$ in $\left[\mathrm{AgO}_{2}\right]$, $\left[\mathrm{AgO}_{4}\right]$, and $\left[\mathrm{WO}_{6}\right]$ clusters are shown as a function of electrons added. An analysis and a comparison of the geometries for a neutral $(\mathrm{N}=0)$ and charged $(\mathrm{N}=10)$ structures shows a pronounced increase in the corresponding Ag-O distances with the addition of electrons. In the $\left[\mathrm{AgO}_{2}\right]$ cluster, the Ag-O distance increases from 2.15 to $2.81 \AA$. In the $\left[\mathrm{AgO}_{4}\right]$ cluster, two different distances are observed: one pair exhibits a similar behaviour to that of the bonds in the $\left[\mathrm{AgO}_{2}\right]$ cluster and has an O-Ag-O angle of approximately $170^{\circ}$; the other pair has an $\mathrm{O}-\mathrm{Ag}-\mathrm{O}$ angle of approximately $108^{\circ}$ and a longer Ag-O distance, which indicates that the atoms detach as the electrons are added. In fact, when $\mathrm{N}=10$, the first pair of $\mathrm{O}$ atoms form an $\mathrm{O}-\mathrm{Ag}-\mathrm{O}$ angle of approximately $178^{\circ}$, whereas the angle of the second pair is reduced to approximately $90^{\circ}$, as shown in Figure 3.

Table 2. Values of $\mathrm{Ag}-\mathrm{O}$ and $\mathrm{W}-\mathrm{O}$ bond distances in the $\left[\mathrm{AgO}_{2}\right],\left[\mathrm{AgO}_{4}\right]$, and $\left[\mathrm{WO}_{6}\right]$ clusters, in $\AA$, as a function of the number of electrons added. The multiplicity of the bond is placed in parenthesis.

\begin{tabular}{ccccccc}
\hline $\mathrm{N}$ & {$\left[\mathrm{AgO}_{2}\right]$} & \multicolumn{2}{c}{$\left[\mathrm{AgO}_{4}\right]$} & \multicolumn{3}{c}{$\left[\mathrm{WO}_{6}\right]$} \\
\hline & $(2)$ & $(2)$ & $(2)$ & $(3)$ & $(1)$ & $(2)$ \\
\hline 0 & 2.15 & 2.23 & 2.44 & 1.83 & 2.06 & 2.11 \\
1 & 2.22 & 2.26 & 2.50 & 1.84 & 2.06 & 2.11 \\
2 & 2.32 & 2.32 & 2.55 & 1.84 & 2.05 & 2.12 \\
3 & 2.46 & 2.43 & 2.57 & 1.83 & 2.05 & 2.15 \\
4 & 2.59 & 2.54 & 2.61 & 1.83 & 2.05 & 2.16 \\
5 & 2.67 & 2.62 & 2.69 & 1.82 & 2.04 & 2.17 \\
6 & 2.66 & 2.57 & 2.77 & 1.83 & 2.04 & 2.17 \\
7 & 2.69 & 2.63 & 2.77 & 1.83 & 2.05 & 2.18 \\
8 & 2.77 & 2.68 & 2.85 & 1.82 & 2.04 & 2.18 \\
9 & 2.79 & 2.67 & 2.89 & 1.83 & 2.05 & 2.18 \\
\hline
\end{tabular}




\begin{tabular}{lllllll}
\hline 10 & 2.81 & 2.75 & 2.91 & 1.82 & 2.06 & 2.18 \\
\hline
\end{tabular}

In the two types of $\left[\mathrm{WO}_{6}\right]$ clusters, we find that the $\mathrm{W}-\mathrm{O}$ distances corresponding to the $\mathrm{W} 2$ and $\mathrm{W} 3$ atoms remain almost unaltered, whereas the distance of the W-O bond corresponding to $\mathrm{W} 1$ decreases smoothly with the addition of electrons. These results show that during electron irradiation, electronic and structural disorder was introduced into the material, thus illustrating the fundamental role of cluster concepts in the formation and growth of $\mathrm{Ag}$ filaments.
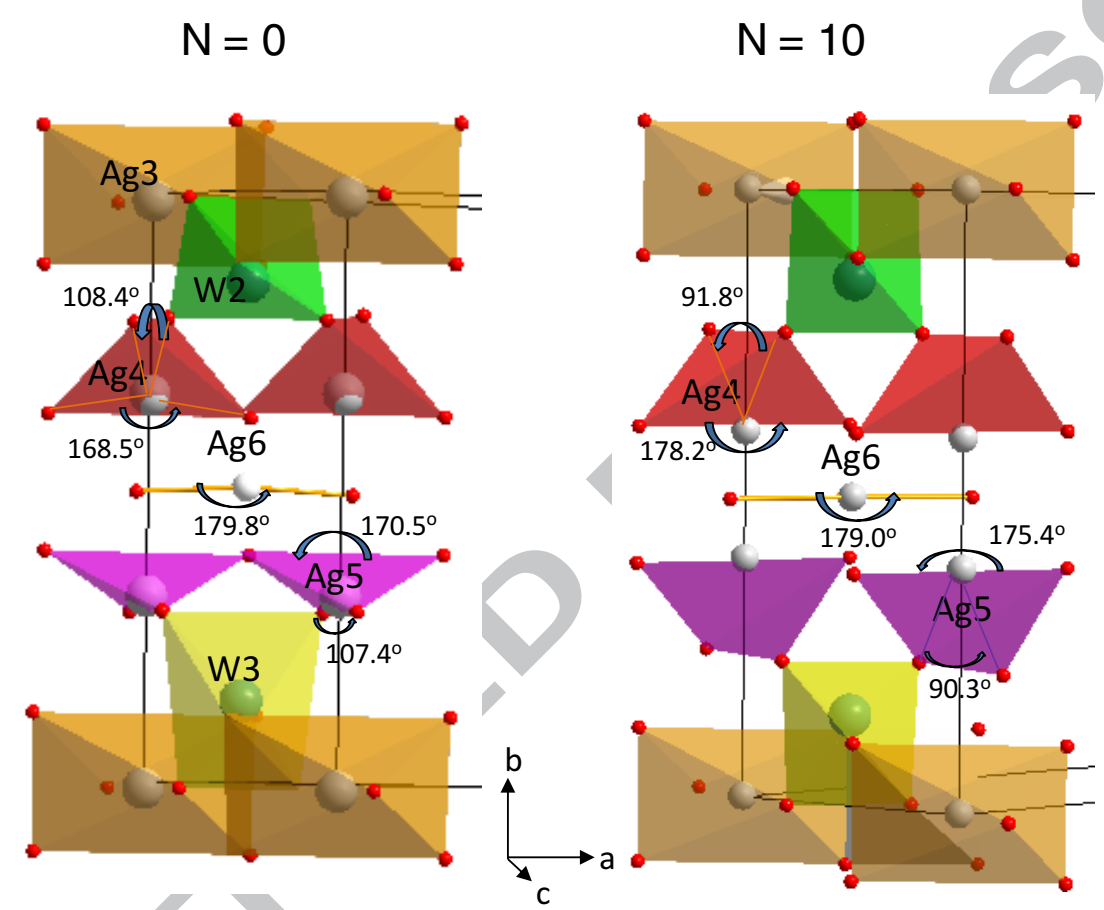

Figure 3. Geometry of neutral $(\mathrm{N}=0)$ and charged $(\mathrm{N}=10)$ structures, focused on distances and angle variations on $\left[\mathrm{AgO}_{2}\right]$ and $\left[\mathrm{AgO}_{4}\right]$ clusters.

Finding zero flux surfaces between two atoms allows the charge of each atom to be calculated. In Table 3, the charge density of the $\mathrm{Ag}$ and $\mathrm{W}$ centres of the $\left[\mathrm{AgO}_{2}\right]$, $\left[\mathrm{AgO}_{4}\right]$, and $\left[\mathrm{WO}_{6}\right]$ clusters is presented as a function of the number of electrons added. Atomic charges were calculated using integrations of the charge density of the atomic basins, $\Omega$, and subtracting the nuclear charge, $\mathrm{Z}$, of the corresponding atom as follows.

$$
\mathrm{q}(\Omega)=\mathrm{Z}_{\Omega}-\mathrm{N}\left(\Omega \text { with } \quad \mathrm { N } \left(\Omega=\int_{\Omega} \rho(\Omega) d r\right.\right.
$$


The average bond distances of $\mathrm{Ag}-\mathrm{Ag}$ as a function of the number of electrons added are reported in Table 4, and the Laplacian of electron density contours on the (100) plane for the neutral $(\mathrm{N}=0)$ structure and charged $(\mathrm{N}=10)$ structures are depicted in Figure 4.

Table 3. Charge density of the $\mathrm{Ag}$ and $\mathrm{W}$ centres in $\left[\mathrm{AgO}_{2}\right],\left[\mathrm{AgO}_{4}\right]$, and $\left[\mathrm{WO}_{6}\right]$ clusters as a function of the number of electrons added. $q(\Omega$ represents the number of valence electrons minus the calculated charge density.

\begin{tabular}{cccc}
\hline $\mathrm{Ne}$ & {$\left[\mathrm{WO}_{6}\right](\mathrm{W} 1)$} & {$\left[\mathrm{AgO}_{4}\right](\mathrm{Ag} 4 / \mathrm{Ag} 5)$} & {$\left[\mathrm{AgO}_{2}\right](\mathrm{Ag} 6)$} \\
\hline 0 & 2.818 & 0.653 & 0.665 \\
1 & 2.794 & 0.596 & 0.566 \\
2 & 2.772 & 0.526 & 0.453 \\
3 & 2.700 & 0.425 & 0.331 \\
4 & 2.679 & 0.354 & 0.204 \\
5 & 2.611 & 0.233 & 0.086 \\
6 & 2.584 & 0.196 & 0.060 \\
7 & 2.545 & 0.176 & 0.032 \\
8 & 2.508 & 0.100 & -0.119 \\
9 & 2.476 & 0.072 & -0.143 \\
10 & 2.455 & 0.069 & -0.159 \\
\hline
\end{tabular}

Table 4. Average Ag-Ag distances (in $\AA$ ) as a function of the number of electrons added.

\begin{tabular}{ccc}
\hline $\mathrm{N}$ & Ag6-Ag4/Ag5 & Ag4-Ag5 \\
\hline 0 & 3.35 & 3.36 \\
1 & 3.24 & 3.00 \\
2 & 3.22 & 2.92 \\
3 & 3.20 & 2.83 \\
4 & 3.19 & 2.75 \\
5 & 3.18 & 2.68 \\
6 & 3.21 & 2.71 \\
\hline
\end{tabular}




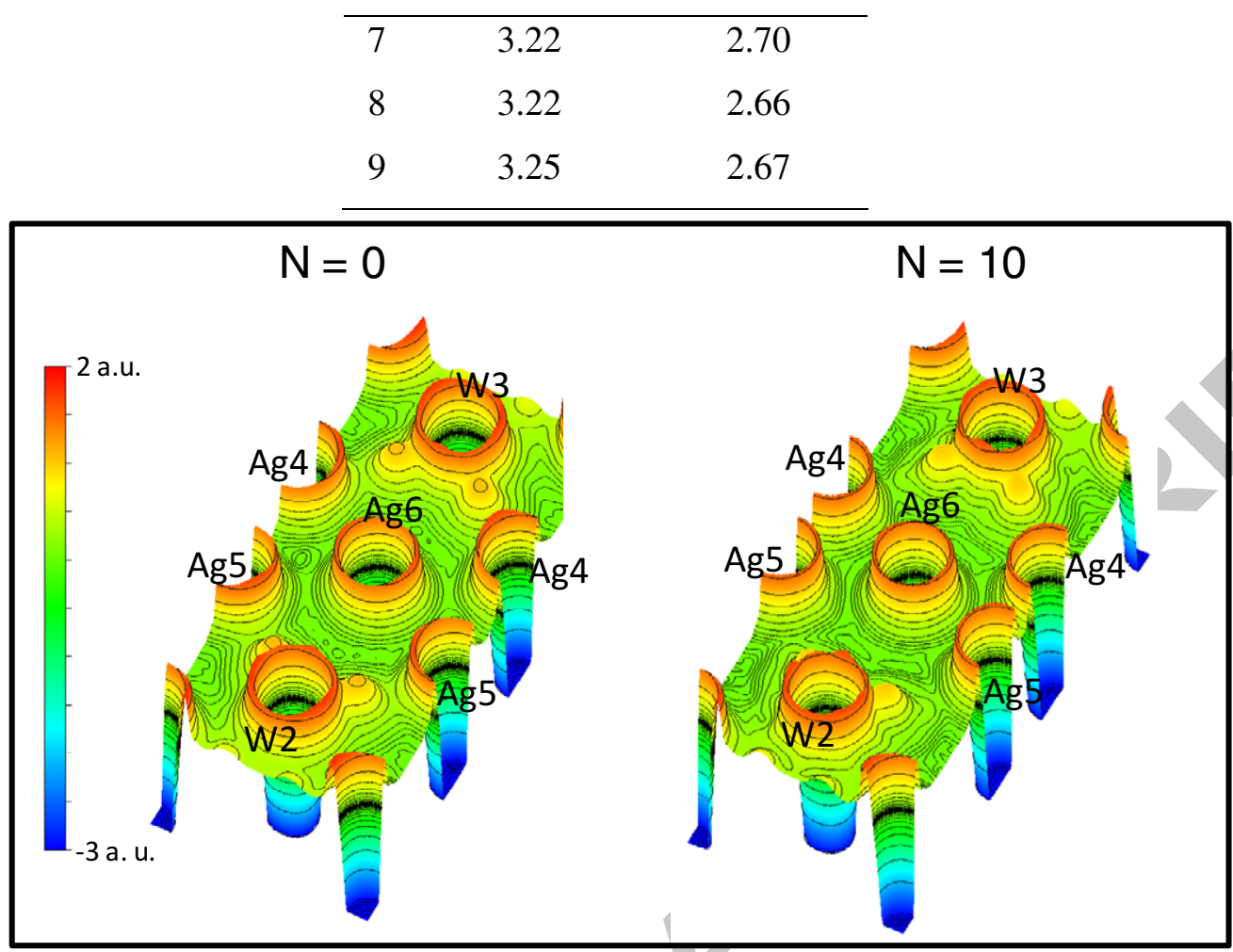

Figure 4. Laplacian of electron density contours on the (100) plane for a neutral $(\mathrm{N}=0)$ structure and a charged $(\mathrm{N}=10)$ structure.

An analysis of the results presented in Figure 4 reveals that the Laplacian of the electron density distribution is enhanced between $\mathrm{Ag} 4$ and $\mathrm{Ag} 5$ at the same time that the $\mathrm{Ag} 4-\mathrm{Ag} 5$ contact distance is shortened when the number of added electrons is increased from $\mathrm{N}=0$ to $\mathrm{N}=10$. In addition, there is an electronic charge density enlargement in the vicinity of $\mathrm{Ag} 6$ atoms on going from $\mathrm{N}=0$ to $\mathrm{N}=10$.

An analysis of the results presented in Table 4 reveals that the Ag6 atoms of the $\left[\mathrm{AgO}_{2}\right]$ clusters are the atoms most prone to reduction. At $\mathrm{N}=7$, the $\mathrm{Ag} 6$ atoms are practically reduced, whereas the $\mathrm{Ag} 4 / \mathrm{Ag} 5$ centres require at least 10 electrons to reach the same state. This behaviour implies the existence of two different paths to obtain metallic $\mathrm{Ag}$, which are associated with the $\left[\mathrm{AgO}_{2}\right]$ and $\left[\mathrm{AgO}_{4}\right]$ clusters. In the case of W atoms that form $\left[\mathrm{WO}_{6}\right]$ clusters, $\mathrm{W} 1$ atoms behave differently than $\mathrm{W} 2$ and $\mathrm{W} 3$ atoms, and a minor decrease in electron density relative to that of $\mathrm{Ag}$ centres is observed (a decrease of 0.2 units at $\mathrm{N}=10$ ). Therefore, the extra electron density added to the material is transferred from one cluster to another through the lattice network, and the Ag-formation process involves both adjacent $\left[\mathrm{AgO}_{2}\right]$ and $\left[\mathrm{AgO}_{4}\right]$ clusters and, to a minor extent, $\left[\mathrm{WO}_{6}\right]$ clusters. During electron irradiation, electronic and structural 
disorder is introduced into the material, indicating the fundamental role that cluster concepts play in the formation and growth of $\mathrm{Ag}$ filaments.

The values of the Laplacian, $\nabla \rho_{\mathrm{bcp}}$, and the charge density, $\rho_{\mathrm{bcp}}$, at the $(3,-1)$ bond critical points $(\mathrm{BCP})$ for $\mathrm{Ag}-\mathrm{O}$ bonds in the $\left[\mathrm{AgO}_{2}\right]$ and $\left[\mathrm{AgO}_{4}\right]$ clusters diminish as the number of electrons is increased, as shown in Figure 5. The effect of adding electrons to the material produces striking differences in the values of the charge density at the $(3,-1)$ BCP and its Laplacian, indicating that these bonds become weaker in favour of the formation of metallic $\mathrm{Ag}$ from both the $\left[\mathrm{AgO}_{2}\right]$ and $\left[\mathrm{AgO}_{4}\right]$ clusters.
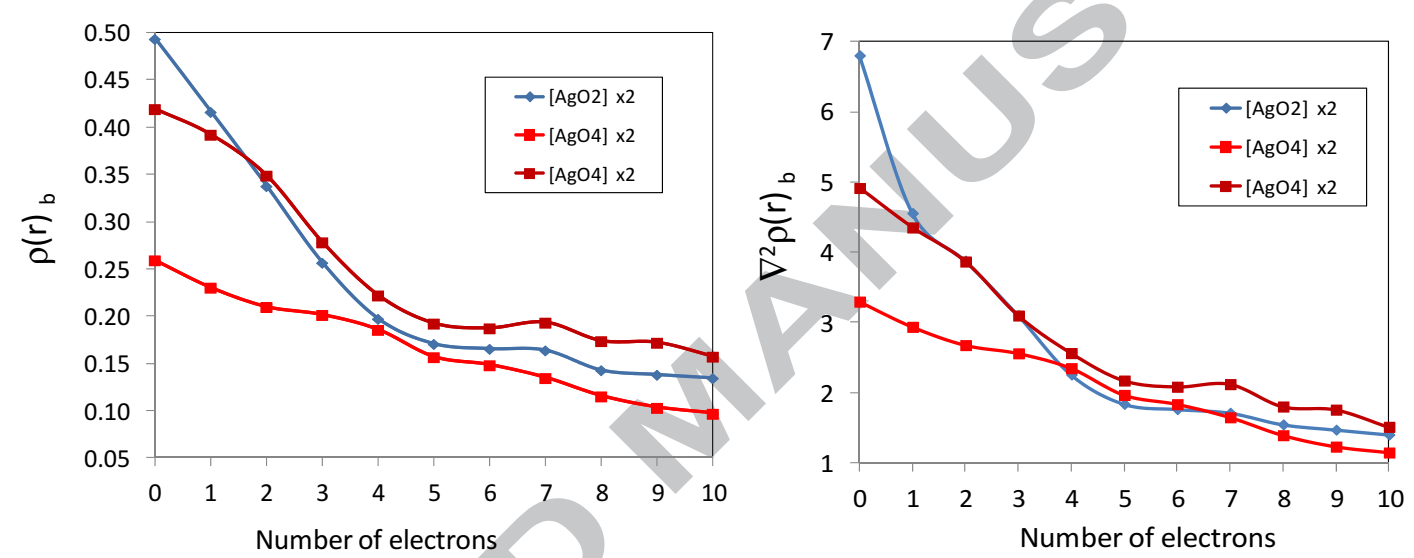

Figure 5. Charge density at the $(3,-1)$ BCPs and its Laplacian in Ag-O bonds for $\left[\mathrm{AgO}_{2}\right]$ and $\left[\mathrm{AgO}_{4}\right]$ clusters as a function of the number of electrons added, $\mathrm{N}$.

\section{ii) $\mathrm{CN}_{3} \mathrm{Mg}_{3}{ }^{+}$decomposition}

The planar hypercoordinate carbon species, including penta-, hexa- and heptacoordinate carbon, have been recently studied by several research groups [209-212]. However, for some $\mathrm{D}_{7 \mathrm{~h}}, \mathrm{D}_{6 \mathrm{~h}}$ and $\mathrm{C}_{2 \mathrm{v}}$ planar hypercoordinate species it has been proved that they were experimentally unviable $[213,214]$. Due to these results, the theoretical chemists have been prompted to find stable planar carbon species to facilitate experimental confirmation, and some hypercoordinate planar carbon species have been proposed to be viable due to their predicted thermodynamic stability [215-218]. To explore the importance of kinetic stability, very recently $\mathrm{Wu}$ et al. have published a paper in which the stability of $\mathrm{CN}_{3} \mathrm{Mg}_{3}{ }^{+}$has been studied [219]. In particular, they have shown that a $\mathrm{D}_{3 \mathrm{~h}}$ isomer with a planar hexacoordinate carbon in the center is kinetically 
stable, whereas those isomers energetically more favourable are kinetically unstable. They reported a barrier of $46.75 \mathrm{kcal} / \mathrm{mol}$ for the ring-opening process at the $\operatorname{CCSD}(\mathrm{T}) /$ aug-cc-pVTZ//MP2/aug-cc-pVTZ level, and hence the kinetic stability of planar $\mathrm{D}_{3 \mathrm{~h}} \mathrm{CN}_{3} \mathrm{Mg}_{3}{ }^{+}$would own its existence in the gas phase synthesis.

To gain a deeper insight in the description of the $\mathrm{D}_{3 \mathrm{~h}} \mathrm{CN}_{3} \mathrm{Mg}_{3}{ }^{+}$opening process, we have performed the joint use of electron localization function ELF and CT by means of TopMod package [220], considering a cubical grid of step size smaller than 0.05 bohr. In this framework, the reaction mechanism can be rationalized in terms of chemical events (bond forming or breaking processes, creation and annihilation of electron pairs) that drive the chemical rearrangement. This analysis allows us to understand the electronic structure and related properties of the reactants as the reaction takes place, providing a further understanding of the chemical reactivity. Starting from the TS, the reaction path has been traced following the intrinsic reaction coordinate (IRC) $[221,222]$, using a Rx in mass-weighted step of $0.05 \mathrm{amu}^{1 / 2}$ bohr until reaching the minimum.

The TS and the two associated minima calculations and the IRC path tracing have been done at the MP2/aug-cc-pVTZ level of theory, using Gaussian 09 code [223]. In such a way, we have obtained a barrier height of $55.0 \mathrm{kcal} / \mathrm{mol}$, in reasonable agreement with the predicted kinetic stability of planar $\mathrm{CN}_{3} \mathrm{Mg}_{3}{ }^{+}$[219].

For each point along the IRC path, the wave function and the ELF analysis has been performed both at the B3LYP/6-31G(d,p) and MP2/aug-cc-pVTZ levels. A comparison between the results obtained at the two theoretical levels is reported in what follows.

The energy profile along the IRC path is reported in Figure 6, and the geometries of the stationary points found are shown in Figure 7 together with the atom numbering. As can be seen, the TS accounts for the ring opening, and the IRC ends up in a stationary point very close in energy to the TS. Wu et al reported a more stable product species for this process after a change in its electronic state from singlet to triplet. However, such electronic state change falls outside the scope of the present work, and we have only characterized the singlet-state ring opening. 


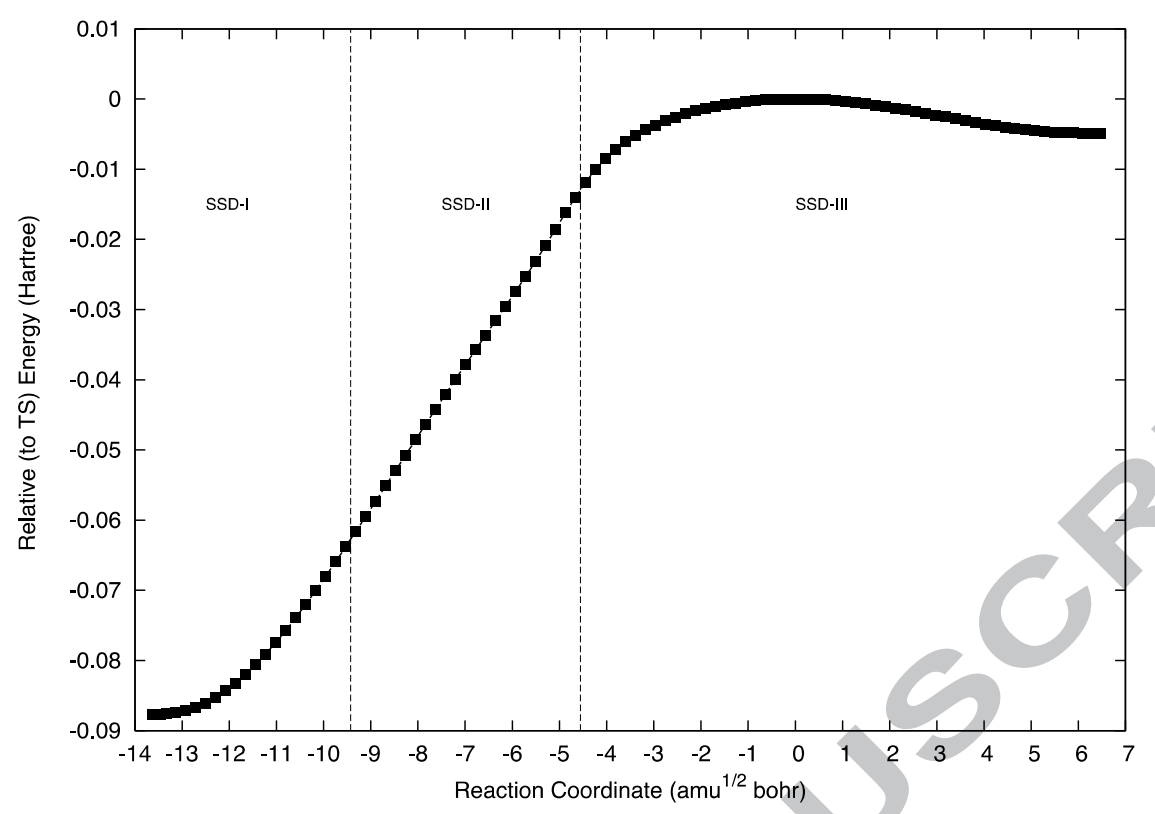

Figure 6. Energy profile for the opening of planar $\mathrm{D}_{3 \mathrm{~h}} \mathrm{CN}_{3} \mathrm{Mg}_{3}{ }^{+}$(left side), calculated by means of the IRC method. Structural stability domains at MP2/aug-cc-pVTZ level are indicated.

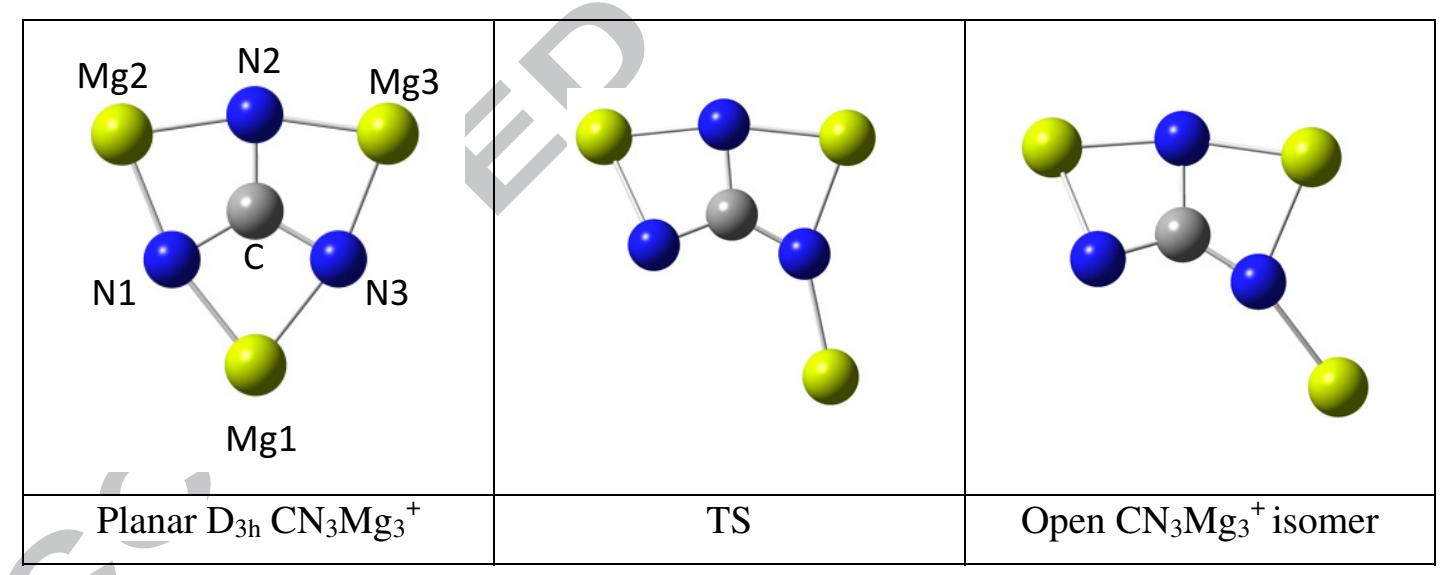

Figure 7. MP2/aug-cc-pVTZ geometries of the indicated stationary points. The depicted bonds indicate bonding interactions, see below.

At the planar $\mathrm{D}_{3 \mathrm{~h}}$ isomer, nineteen basins can be found at the B3LYP/6-31G(d,p) level, corresponding to the seven core basins, nine disynaptic basins (accounting for the three $\mathrm{C}-\mathrm{N}$ and the six N-Mg bonds), and three monosynaptic basins associated with the $\mathrm{Mg}$ atoms. At the MP2/aug-cc-pVTZ level, only sixteen basins are found: the three 
monosynaptic basins previously described as associated with the $\mathrm{Mg}$ atoms cannot be found. In Figure 8 the ELF localization domains found for this stationary point at the MP2/aug-cc-pVTZ level are depicted at different $\eta$ isosurface values, while the ELF localization domains found at the B3LYP/6-31G(d,p) level are reported as supporting information.

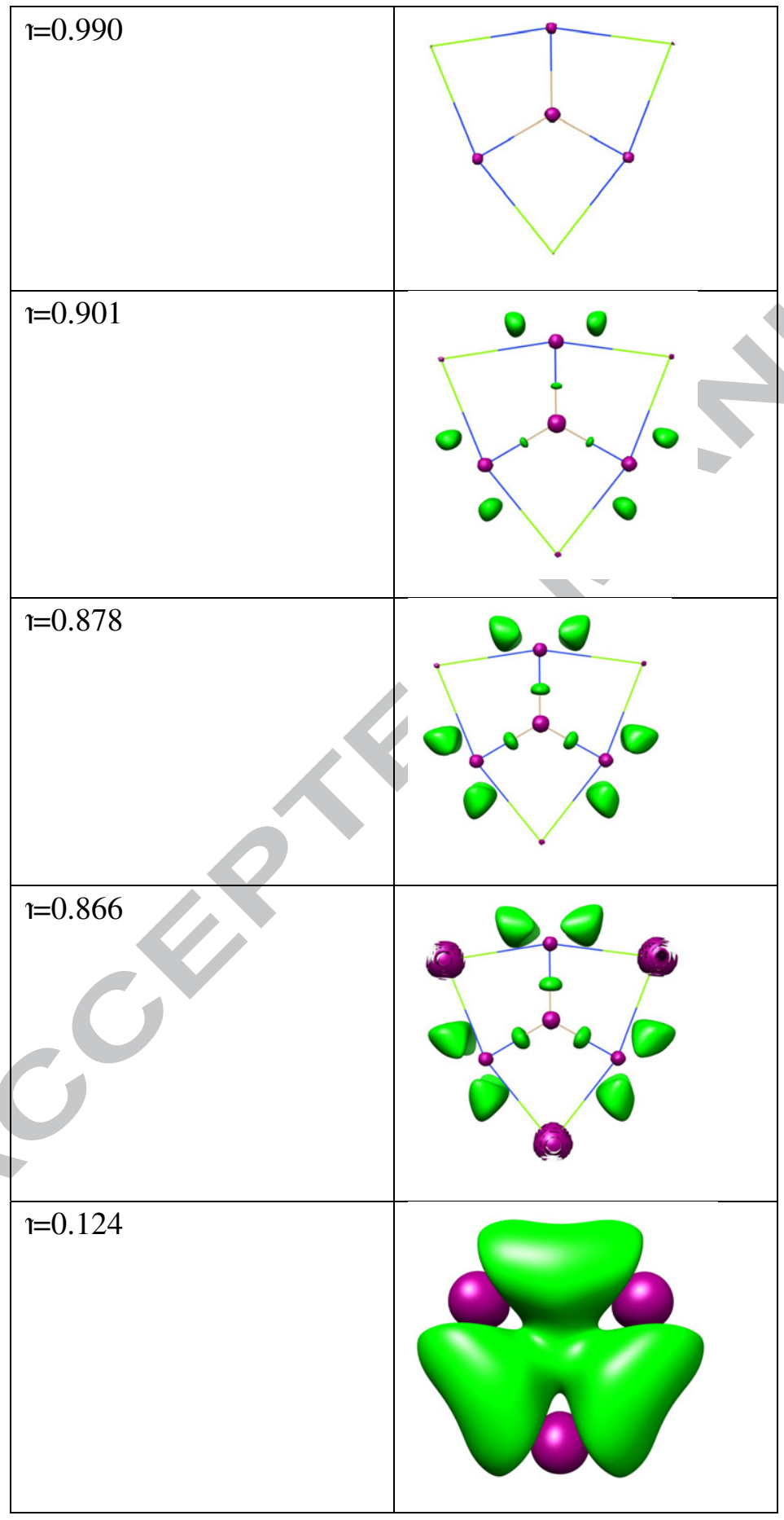


Figure 8. ELF localization domains for the planar $D_{3 h}$ isomer, at different pisosurface values, MP2 results. The color code is as follows: green, disynaptic basins; red, monosynaptic basins; purple, core basins.

Following the snapshots reported in Figure 8 it can be seen that at an ELF isosurface value as high as 0.99 the core basins of the seven atoms can already be viewed. These basins stand for the internal core electrons. Reducing the pisosurface value to 0.901 the disynaptic basins corresponding to the $\mathrm{N}-\mathrm{Mg}$ bonding interactions appear first, followed by the disynaptic basins corresponding to the $\mathrm{C}-\mathrm{N}$ bonds. The core basins corresponding to $\mathrm{Mg}$ atoms change its shape, increasing it at a pisosurface value of 0.866 , due to the 2 s electrons. Finally, the monosynaptic basins associated with the magnesium atoms appear at a nisosurface value as low as 0.124 at B3LYP level (see

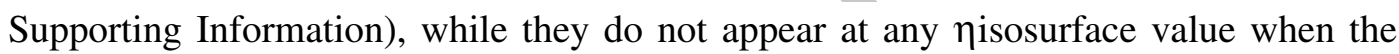
MP2 level of theory is used. This fact, together with the very low population $(0.02$ electrons) of these monosynaptic basins, leads us to think that they are spurious, and we have not considered them in the following discussion.

An interesting point is that the disynaptic basins corresponding to the $\mathrm{N}-\mathrm{Mg}$ bonding interactions are not located in the line connecting the $\mathrm{N}$ and $\mathrm{Mg}$ atoms, so that the N-Mg bonds cannot be described as standard obonds; instead they have an "out-ofline" $\pi$ character. This result is in nice agreement with the $\mathrm{Wu}$ et al. study [219]: by using NBO analysis, they describe the molecule as possessing aromaticity with $\pi$ MOs delocalized on the whole molecule and extending outside the straight $\mathrm{N}-\mathrm{Mg}$ lines. Another interesting point is that no disynaptic basins have been found between the $\mathrm{C}$ and the $\mathrm{Mg}$ atoms. Therefore, from an ELF standpoint if no electron pairing takes place between $\mathrm{C}$ and $\mathrm{Mg}$, it should be concluded that there is no covalent bond between them, and the interactions might be mainly ionic. This again is in agreement with the NBO analysis of $\mathrm{Wu}$ et al., who report a negligible Wiberg bond order between $\mathrm{C}$ and $\mathrm{Mg}$, suggesting that the interactions between them are not covalent.

When moving along the IRC, the topology of the system changes by changing the number and/or nature of the ELF localization domains. The consecutive points of the IRC that own the same number and nature of ELF basins constitute a structural stability domain (SSD), and hence a chemical process can be described by analyzing the 
different SSDs found in the way from reactants to products. For the opening of the planar $\mathrm{D}_{3 \mathrm{~h}} \mathrm{CN}_{3} \mathrm{Mg}_{3}{ }^{+}$process three SSDs have been found, and they are indicated in Figure 6. Without taking into account the spurious monosynaptic basins associated with $\mathrm{Mg}$ atoms, the difference between the results obtained at the two calculation levels (compare Figure 6 with Figure $1 \mathrm{~S}$ in Supporting Information) is the value of the reaction coordinate at which the turning points between consecutive SSD's appear. At the MP2 level, the SSD-I to SSD-II turning point takes place at $\mathrm{s} \approx-9.43 \mathrm{amu}^{1 / 2} \mathrm{bohr}$ while the turning point between SSD-II and SSD-III can be found at $\mathrm{s} \approx-4.56$ $\mathrm{amu}^{1 / 2}$ bohr. At the B3LYP level the first turning point is found at a slightly earlier stage of the process ( $\mathrm{s} \approx-10.07 \mathrm{amu}^{1 / 2} \mathrm{bohr}$ ), and the second catastrophe is also earlier ( $\mathrm{s} \approx-$ $\left.6.67 \mathrm{amu}^{1 / 2} \mathrm{bohr}\right)$.

The series of SSDs found can be viewed as a sequence of chemical events taking place in the $\mathrm{CN}_{3} \mathrm{Mg}_{3}{ }^{+}$opening. This has been sketched in Scheme 1, depicted from the perspective of the ELF analysis, in which full lines and ellipses represent disynaptic and monosynaptic basins, respectively.

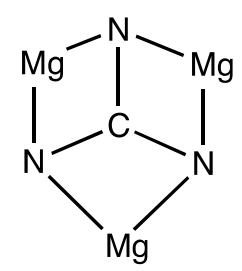

SSD-I

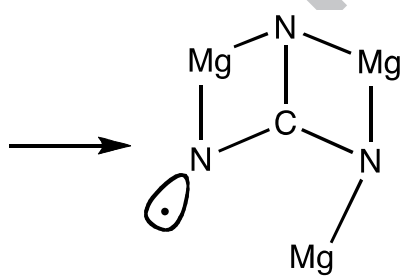

SSD-II

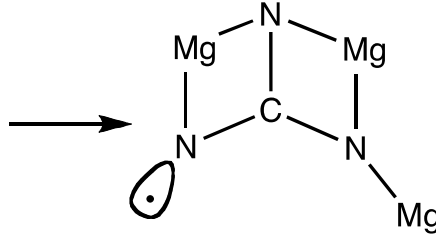

SSD-III

Scheme 1. Representation of the opening of planar $\mathrm{D}_{3 \mathrm{~h}} \mathrm{CN}_{3} \mathrm{Mg}_{3}{ }^{+}$from the ELF perspective.

The first catastrophe, between SSD-I and SSD-II, accounts for the transformation of the $\mathrm{N} 1-\mathrm{Mg} 1$ bonding interaction into a monosynaptic basin on the $\mathrm{N} 1$ atom. Then a new monosynaptic basin appears on the Mg1 atom and in this way SSDIII is reached.

Snapshots of the ELF basins for some selected points along the IRC, representing the different SSDs found, are depicted in Figure 9 for the MP2 results. An 
equivalent figure accounting with the B3LYP results is reported in Supporting Information. In both figures we have chosen an isosurface value of 0.866 because the different basins found can be observed, except the spurious monosynaptic basins associated with the Mg atoms as obtained at the B3LYP level.

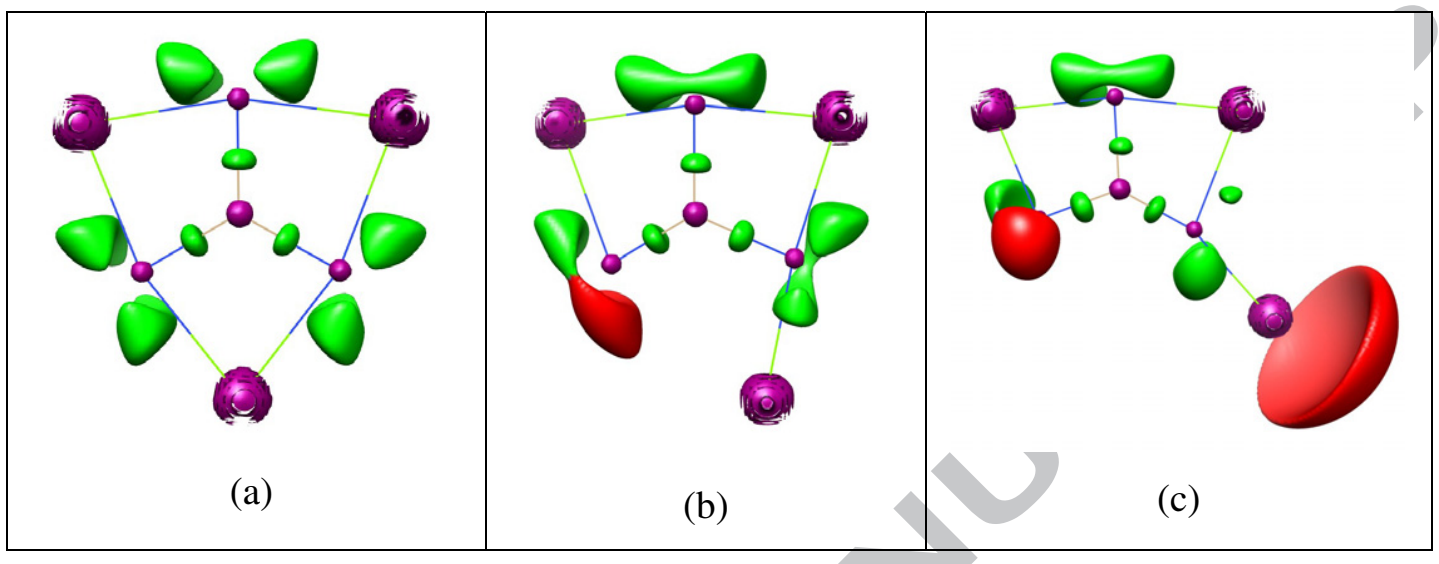

Figure 9. Snapshots of the ELF localization domains (₹0.866 isosurface) for selected points along the IRC, as calculated at the MP2/aug-cc-pVTZ level: (a) Planar $\mathrm{D}_{3 \mathrm{~h}}$ $\mathrm{CN}_{3} \mathrm{Mg}_{3}{ }^{+}$, belonging to SSD-I, (b) point at $\mathrm{s} \approx-6.357 \mathrm{amu}^{1 / 2}$ bohr belonging to SSD-II, (c) open $\mathrm{CN}_{3} \mathrm{Mg}_{3}{ }^{+}$species, belonging to SSD-III.

As can be seen both in Figure 9 and Figure 3S, at SSD-II the bonding basin $\mathrm{V}(\mathrm{Mg} 1, \mathrm{~N} 1)$ changes its nature into a monosynaptic (red) basin on N1, while at SSD-III a monosynaptic basin appears on $\mathrm{Mg} 1$.

The evolution of some basin populations along the IRC path are reported in Figure 10 for the MP2 results, and in Supporting Information for the B3LYP results. 


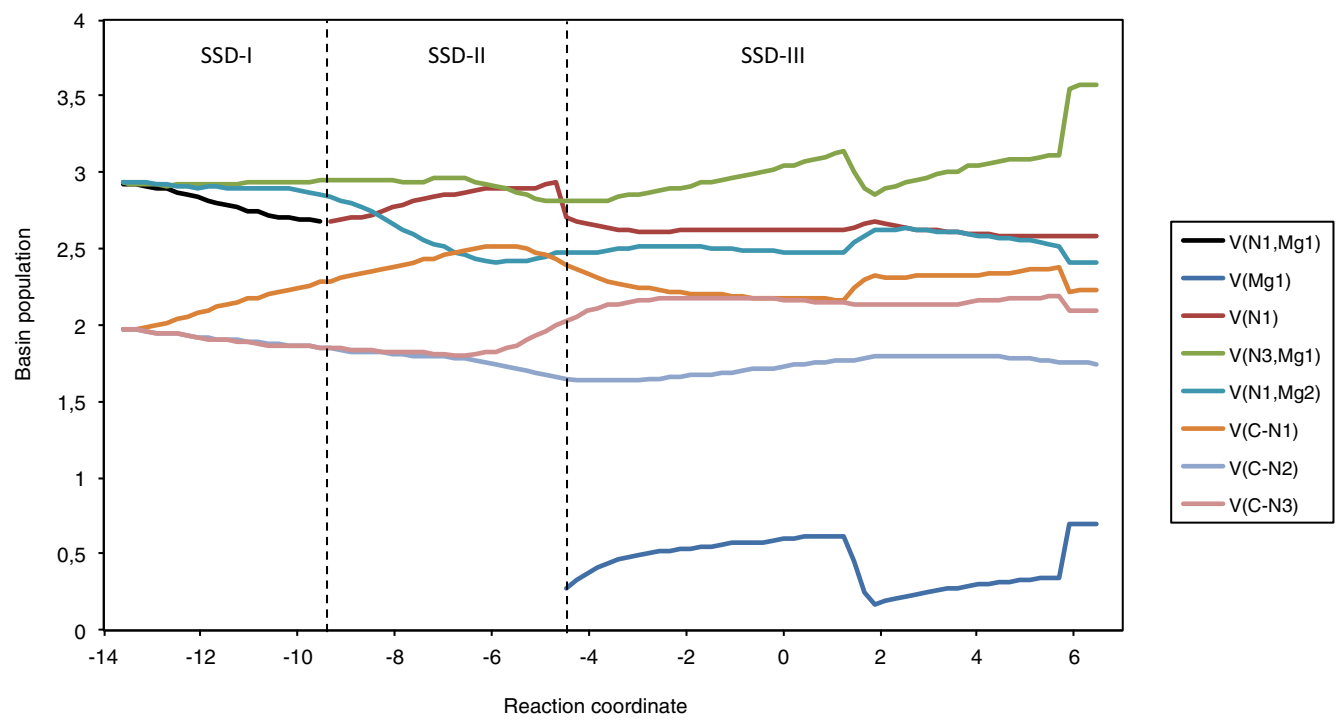

Figure 10. Population evolution of some basins as calculated at the MP2/aug-cc-pVTZ level along the IRC path. Dashed lines separate the structural stability domains found, which are indicated.

As can be seen in Figure 10, along the SSD-I the population of the $\mathrm{V}(\mathrm{N} 1, \mathrm{Mg} 1)$ disynaptic basin lowers from 2.93 to 2.68 , due to the breaking of the $\mathrm{N} 1-\mathrm{Mg} 1$ bond as the process advances. Then the turning point between SSD-I and SSD-II is found and the basin changes its disynaptic nature, becoming monosynaptic and associated to N1. Along SSD-II the population of this monosynaptic basin grows up to achieve a value of 2.94 in its last point. The position of the basin also changes approaching to N1, and the larger electronegativity of the $\mathrm{N}$ atom explains the electron population increasing of this basin. In any case, the population of the $\mathrm{V}(\mathrm{N} 1)$ basin goes down from 2.94 at SSD-II to 2.58 at the end of SSD-III. Concomitantly, the population of $\mathrm{V}(\mathrm{Mg} 1)$ monosynaptic basin, increases from 0.27 at the beginning of SSD-III to 0.69 at the end of SSD-III.

On the other hand, the population of $\mathrm{V}(\mathrm{N} 3, \mathrm{Mg} 1)$ remains more or less constant (oscillating between 2.91 and 2.95) along SSD-I. Then it slightly diminishes along SSDII (to 2.81) and it grows up from 2.81 to 3.58 along of SSD-III. However, at $\mathrm{s} \approx 1.27$ $\mathrm{amu}^{1 / 2}$ bohr, a sudden lowering of its population is detected from 3.14 to 2.86 . In fact, at this point of the IRC, sudden changes more or less significant are detected in the populations of several basins due to internal rearrangement of the electron distribution since the molecule looses its planarity as the reaction proceeds. In particular, the 
population diminishes on the basins related with $\mathrm{Mg} 1$ and increases on some disynaptic basins mainly related with $\mathrm{N} 1$. Therefore, the population of the $\mathrm{V}(\mathrm{Mg} 1)$ basin diminishes from 0.62 to 0.17 , and the population of the $\mathrm{V}(\mathrm{N} 2, \mathrm{Mg} 3)$ also goes slightly down. On the other hand, the populations of the $\mathrm{V}(\mathrm{C}, \mathrm{N} 1)$ and $\mathrm{V}(\mathrm{N} 1, \mathrm{Mg} 2)$ grow up, as it is also sensed in the $\mathrm{V}(\mathrm{N} 2, \mathrm{Mg} 2)$ and $\mathrm{V}(\mathrm{N} 3, \mathrm{Mg} 3)$ basins (data not shown in Figure 10). This electron redistribution can also be related with the changes on electrostatic charges on the atoms in the molecule, that take place in these IRC points. These electrostatic changes can mainly be sensed on $\mathrm{Mg} 1$, whose positive charge increases from +0.89 to +1.02 , and on $\mathrm{N} 1$, whose negative charge also increases from -0.69 to -0.80. At B3LYP level, such sudden variations on the basins population take place at earlier stages, see Figure 4S. At the MP2 level, an opposite sudden change in some basin populations is found at $\mathrm{s} \approx 5.902 \mathrm{amu}^{1 / 2}$ bohr. This second sudden change is not observed at the B3LYP level.

The population of the $\mathrm{V}(\mathrm{N} 1, \mathrm{Mg} 2)$ disynaptic bonding basin lowers as the reaction proceeds until a minimum is reached around $\mathrm{s} \approx-5.721 \mathrm{amu}^{1 / 2} \mathrm{bohr}$, within SSD-II, and at the same time the population of the $\mathrm{V}(\mathrm{C}, \mathrm{N} 1)$ disynaptic basin increases until a maximum is reached at the same point along the IRC. From this point onwards, the population of $\mathrm{V}(\mathrm{C}, \mathrm{N} 1)$ diminishes (except for the changes seen by the last part of SSD-III). At the same time, the population of the bonding V(C,N3) disynaptic basin grows up. Taking the entire data, a migration of the electron density can be sensed from the left (N1-Mg1 bond first, $\mathrm{N} 1$ after, and $\mathrm{N} 1-\mathrm{Mg} 2$ bond) to the right ( $\mathrm{Mg} 1$ and $\mathrm{C}-\mathrm{N} 3$ bond) side of the molecule as the reaction takes place, as expected because of the accumulation of electron density on the $\mathrm{Mg} 1$ atom and its surroundings.

The description of the basins population evolution along the IRC at the B3LYP level is quite similar, as can be seen in Figure $4 \mathrm{~S}$. The main difference, as already indicated, is sensed late along SSD-III, in the points where sudden changes are found.

\section{Conclusions and outlook}

In science and then in physics and chemistry, two faces are mandatory to support any theory, i.e. a mathematical formalism disclosing the basic entities of the theory and their mathematical relationships, and concepts to interpret the theory. However, the 
connection between the mathematical formalism of a theory and its interpretation is always subtle.

To guide us towards an understanding of many scientific phenomena, simple concepts are necessary, even they are incomplete initially. An illustration of this fact, the chemical bond and their reorganization are one of the successful concepts in chemistry in interpreting and predicting many chemical phenomena related to structure and chemical reactivity, respectively. Both concepts provide a qualitative description to understand the nature of molecular electronic structure and predict the molecular reactivity. However, they have not clear physical nature and deep definition. To circumvent this difficulty, the preceding examples, from collaborative work and many other studies in the literature, show the benefits of a joint experimental and theoretical approach to problems.

Here we show how the theory, based on the quantum chemical topology analysis, provides a general set of reasons why these concepts and models can be thought to occur. It is composed of a mathematical formalism and a "chemical interpretation" that introduces the glue linking the formalism and chemical concepts previously defined in the chemical discourse of structure and chemical reactivity. As Einstein remarked: "It can scarcely be denied that the supreme goal of all theory is to make the irreducible basic elements as simple and as few as possible without having to surrender the adequate representation of a single datum of experience.' [224]

Using the present procedure we can model bonding patterns in solid state structure and molecules, as well as the molecular mechanisms of chemical reactions. Very recently, Contreras-García [225] have provided guides to visualize and to define in an unequivocal manner chemically interesting regions: atoms, bonding and lone pairs, etc. with the identification of bonding paths and non covalent interactions by means of topological analysis of scalar functions based on the electron density. To capture this aim, two different examples have been selected: (i) The Ag nucleation and formation on $\alpha \mathrm{Ag}_{2} \mathrm{WO}_{4}$ provoked by the electron-beam irradiation, has been investigated by means of a QTAIM study, (ii) the decomposition of stable planar hypercoordinate carbon species, $\mathrm{CN}_{3} \mathrm{Mg}_{3}{ }^{+}$, has been analyzed by the joint use of ELF plus CT.

We believe that our representation can be used in student courses and in current textbooks. We also believe that our theoretical findings can serve as a general guideline for the study and analysis of the chemical structure and reaction mechanisms. It is an ultimate example of a cross-disciplinary field, bringing together experimental and 
expertise from physical, organic, inorganic, and mechanistic chemistry, materials engineering, and catalysis. One of the major reasons was that it gave, for the first time, a common platform for theoreticians and experimentalists together, who were otherwise entrenched in their very different points of view; on the other, gave a common language to speak about the very same quantities (e.g. the topological analysis of the static electron density) and to compare theory and experiment without prejudice. The future is bright to unravel complex chemical processes.

\section{Acknowledgements}

The authors are grateful to Generalitat Valenciana for Prometeo/2009/053 project and for PrometeoII/2014/022, Ministerio de Economía y Competitividad (Spain) for project CTQ-2012-36253-C03-02, and Universitat Jaume I for project P1·1B201340. The authors are also grateful to the Servei d'Informàtica, Universitat Jaume I for generous allocation of computer time.

\section{Supporting Information Available}

Figures $1 \mathrm{~S}$ to $4 \mathrm{~S}$. This material is available free of charge from http://www.elsevier.com

\section{References}

[1] L. Pauling, General chemistry : an introduction to descriptive chemistry and modern chemical theory, W.H. Freeman, San Francisco, 1947.

[2] Statement by G. M. Whitesides, in the Opening Plenary Lecture of the 92nd Canadian Chemistry Conference, 30 May 2009, Hamilton, Ontario, Canada (personal communication by K.R.).

[3] R.S. Mulliken, Assignment of quantum numbers for electrons in molecules. I, Phys. Rew. 32 (1928) 186-222.

[4] W. Heitler, F. London, Reciprocal action of neutral atoms and homopolar combination according to quantum mechanics, Z. Phys. 44 (1927) 455-472.

[5] S. Shaik, P.C. Hiberty, A chemist's guide to valence bond theory, WileyInterscience, Hoboken, N.J., 2008.

[6] J.P. Foster, F. Weinhold, Natural hybrid orbitals, J. Am. Chem. Soc. 102 (1980) 7211-7218.

[7] R.B. Woodward, R. Hoffmann, The conservation of orbital symmetry, Verlag Chemie GmbH Academic Press, Weinheim New York, 1970. 
[8] K. Fukui, Recognition of stereochemical paths by orbital interaction, Acc. Chem. Res. 4 (1971) 57-64.

[9] R.A. Marcus, Chemical + electrochemical electron-transfer theory, Annu. Rev. Phys. Chem. 15 (1964) 155-196.

[10] Theories and Models for Chemical Bonding edited by Gernot Frenking, S. Shaik. Wiley-VCH, 2014, and references therein

[11] C.A. Coulson, Present state of molecular structure calculations, Rev. Mod. Phys. 32 (1960) 170-177.

[12] L. Gross, F. Mohn, N. Moll, P. Liljeroth, G. Meyer, The chemical structure of a molecule resolved by atomic force microscopy, Science 325 (2009) 1110-1114.

[13] L. Gross, F. Mohn, N. Moll, B. Schuler, A. Criado, E. Guitian, D. Pena, A. Gourdon, G. Meyer, Bond-order discrimination by atomic force microscopy, Science 337 (2012) 1326-1329.

[14] L. Gross, Recent advances in submolecular resolution with scanning probe microscopy, Nature Chemistry 3 (2011) 273-278.

[15] D.G. de Oteyza, P. Gorman, Y.-C. Chen, S. Wickenburg, A. Riss, D.J. Mowbray, G. Etkin, Z. Pedramrazi, H.-Z. Tsai, A. Rubio, M.F. Crommie, F.R. Fischer, Direct imaging of covalent bond structure in single-molecule chemical reactions, Science 340 (2013) 1434-1437.

[16] J. Lu, K.P. Loh, Single-molecule chemical reactions tracked at the atomic-bond level, Angew. Chem. Int. Edit. 52 (2013) 13521-13523.

[17] P. Ball, Beyond the bond, Nature 469 (2011) 26-28.

[18] C.W. Wilson, Jr., W.A. Goddard, III, Exchange kinetic energy, contragradience, and chemical binding, Chem. Phys. Lett. 5 (1970) 45-49.

[19] W. Kutzelnigg, The Physical Origin of the Chemical Bond, in: Z.B. Maksic (Ed.) Theoretical Models of Chemical Bonding: Part 2, Springer-Verlag, Berlin, 1990, pp. 143.

[20] K. Ruedenberg, Physical nature of chemical bond, Rev. Mod. Phys. 34 (1962) 326376.

[21] R.F.W. Bader, W.H. Henneker, Ionic bond, J. Am. Chem. Soc. 87 (1965) 30633068 .

[22] G. Sini, P. Maitre, P.C. Hiberty, S. Shaik, Covalent, ionic and resonating single bonds, Theochem-J. Mol. Struc. 75 (1991) 163-188.

[23] D.B. Chesnut, A Simple Definition of Ionic Bond Order, J. Chem. Theory Comput. 4 (2008) 1637-1642.

[24] S. Shaik, D. Danovich, W. Wu, P.C. Hiberty, Charge-shift bonding and its manifestations in chemistry, Nature Chemistry 1 (2009) 443-449.

[25] J.A. Gamez, M. Yanez, [FAAF] $(\mathrm{A}=\mathrm{O}, \mathrm{S}, \mathrm{Se}, \mathrm{Te})$ or How electrostatic interactions influence the nature of the chemical bond, J. Chem. Theory Comput. 9 (2013) 5211-5215.

[26] W.A. Goddard, III, L.B. Harding, The description of chemical Fbonding from ab initio calculations, Annu. Rev. Phys. Chem. 29 (1978) 363-396 .

[27] A. Kovacs, C. Esterhuysen, G. Frenking, The nature of the chemical bond revisited: An energy-partitioning analysis of nonpolar bonds, Chem-Eur. J. 11 (2005) 1813-1825.

[28] R. Ponec, D.L. Cooper, Anatomy of bond formation. Bond length dependence of the extent of electron sharing in chemical bonds from the analysis of domain-averaged Fermi holes, Faraday Discuss. 135 (2007) 31-42. 
[29] R. Ponec, Anatomy of bond formation. Domain-averaged fermi holes as a tool for the study of the nature of the chemical bonding in $\mathrm{Li}_{2}, \mathrm{Li}_{4}$, and $\mathrm{F}_{2}, \mathrm{~J}$. Phys. Chem. A 111 (2007) 11294-11301.

[30] T. Bitter, K. Ruedenberg, W.H.E. Schwarz, Toward a physical understanding of electron-sharing two-center bonds. I. General aspects, Journal of Computational Chemistry, 28 (2007) 411-422.

[31] J.A. Harrison, The hyperbolic chemical bond: Fourier analysis of ground and first excited state potential energy curves of HX (X= H-Ne), J. Phys. Chem. A 112 (2008) 8070-8085.

[32] K. Ruedenberg, M.W. Schmidt, Physical understanding through variational reasoning: electron sharing and covalent bonding, J. Phys. Chem. A 113 (2009) 19541968.

[33] K. Ando, Electron wave packet modeling of chemical bonding: floating and breathing minimal packets with perfect-pairing valence-bond spin coupling, Chem. Phys. Lett. 523 (2012) 134-138.

[34] H. Jacobsen, Bond descriptors based on kinetic energy densities reveal regions of slow electrons - Another look at aromaticity, Chem. Phys. Lett. 582 (2013) 144-147.

[35] I. Mayer, Covalent Bonding: The role of exchange effects, J. Phys. Chem. A 118 (2014) 2543-2546.

[36] F. Fantuzzi, M.A.C. Nascimento, The description of polar chemical bonds from the quantum mechanical interference perspective, J. Chem. Theory Comput. 10 (2014) 2322-2332.

[37] F. Fantuzzi, T.M. Cardozo, M.A. Chaer Nascimento, The role of quantummechanical interference and quasi-classical effects in conjugated hydrocarbons, Phys. Chem. Chem. Phys. 14 (2012) 5479-5488.

[38] F.S. Vieira, F. Fantuzzi, T.M. Cardozo, M.A. Chaer Nascimento, Interference energy in $\mathrm{C}-\mathrm{H}$ and $\mathrm{C}-\mathrm{C}$ bonds of saturated hydrocarbons: dependence on the type of chain and relationship to bond dissociation energy, J. Phys. Chem. A 117 (2013) 40254034.

[39] S. Shaik, D. Danovich, B. Silvi, D.L. Lauvergnat, P.C. Hiberty, Charge-shift bonding. A class of electron-pair bonds that emerges from valence bond theory and is supported by the electron localization function approach, Chem-Eur. J. 11 (2005) 63586371.

[40] S. Jenkins, S.R. Kirk, A. Guevara-Garcia, P.W. Ayers, E. Echegaray, A. ToroLabbe, The mechanics of charge-shift bonds: A perspective from the electronic stress tensor, Chem. Phys. Lett. 510 (2011) 18-20.

[41] H.S. Rzepa, The rational design of helium bonds, Nature Chemistry, 2 (2010) 390393.

[42] H. Zhang, D. Danovich, W. Wu, B. Braida, P.C. Hiberty, S. Shaik, Charge-shift bonding emerges as a distinct electron-pair bonding family from both valence bond and molecular orbital theories, J. Chem. Theory Comput. 10 (2014) 2410-2418.

[43] H. Jacobsen, Topology maps of bond descriptors based on the kinetic energy density and the essence of chemical bonding, Phys. Chem. Chem. Phys. 15 (2013) 5057-5066.

[44] L. Pauling, The nature of the chemical bond and the structure of molecules and crystals; an introduction to modern structural chemistry, 3d ed., Cornell University Press, Ithaca, New.York, 1960.

[45] R.G. Parr, P.W. Ayers, R.F. Nalewajski, What is an atom in a molecule?, J. Phys. Chem. A, 109 (2005) 3957-3959. 
[46] H. Jacobsen, Kinetic energy density and covalent bonding. A complementary analysis at the border of bond and no bond, Dalton Trans. 39 (2010) 5426-5428.

[47] D.G. Truhlar, R. Steckler, M.S. Gordon, Potential energy surfaces for polyatomic reaction dynamics, Chem. Rev. 87 (1987) 217-236.

[48] G.C. Schatz, The analytical representation of electronic potential-energy surfaces, Rev. Mod. Phys. 61 (1989) 669-688.

[49] H.B. Schlegel, Adv. Chem. Phys. 67 (1987) 249.

[50] E. Kraka, D. Cremer, Computational analysis of the mechanism of chemical reactions in terms of reaction phases: hidden intermediates and hidden transition states, Acc. Chem. Res. 43 (2010) 591-601.

[51] P. Pechukas, Transition state theory, Annu. Rev. Phys. Chem. 32 (1981) 159-177.

[52] S.J. Klippenstein, V.S. Pande, D.G. Truhlar, Chemical kinetics and mechanisms of complex systems: a perspective on recent theoretical advances, J. Am. Chem. Soc. 136 (2014) 528-546.

[53] B.T. Sutcliffe, The idea of a potential energy surface, Mol. Phys. 104 (2006) 715722.

[54] A.H. Zewail, Femtochemistry: Atomic-Scale Dynamics of the Chemical Bond, J. Phys. Chem. A 104 (2000) 5660-5694.

[55] A.H. Zewail, Four dimensional electron microscopy, Science 328 (2010) 187-193.

[56] H.N. Chapman, P. Fromme, A. Barty, T.A. White, R.A. Kirian, A. Aquila, M.S. Hunter, J. Schulz, D.P. DePonte, U. Weierstall, R.B. Doak, F.R.N.C. Maia, A.V. Martin, I. Schlichting, L. Lomb, N. Coppola, R.L. Shoeman, S.W. Epp, R. Hartmann, D. Rolles, A. Rudenko, L. Foucar, N. Kimmel, G. Weidenspointner, P. Holl, M. Liang, M. Barthelmess, C. Caleman, S. Boutet, M.J. Bogan, J. Krzywinski, C. Bostedt, S. Bajt, L. Gumprecht, B. Rudek, B. Erk, C. Schmidt, A. Hömke, C. Reich, D. Pietschner, L. Strüder, G. Hauser, H. Gorke, J. Ullrich, S. Herrmann, G. Schaller, F. Schopper, H. Soltau, K.-U. Kühnel, M. Messerschmidt, J.D. Bozek, S.P. Hau-Riege, M. Frank, C.Y. Hampton, R.G. Sierra, D. Starodub, G.J. Williams, J. Hajdu, N. Timneanu, M.M. Seibert, J. Andreasson, A. Rocker, O. Jönsson, M. Svenda, S. Stern, K. Nass, R. Andritschke, C.-D. Schröter, F. Krasniqi, M. Bott, K.E. Schmidt, X. Wang, I. Grotjohann, J.M. Holton, T.R.M. Barends, R. Neutze, S. Marchesini, R. Fromme, S. Schorb, D. Rupp, M. Adolph, T. Gorkhover, I. Andersson, H. Hirsemann, G. Potdevin, H. Graafsma, B. Nilsson, J.C.H. Spence, Femtosecond X-ray protein nanocrystallography, Nature 470 (2010) 73-77.

[57] L.R. Khundkar, A.H. Zewail, Ultrafast molecular reaction dynamics in real-time progress over a decade, Annu. Rev. Phys. Chem. 41 (1990) 15-60.

[58] F. Krausz, M. Ivanov, Attosecond physics, Rev. Mod. Phys. 81 (2009) 163-234.

[59] L. Gallmann, C. Cirelli, U. Keller, Attosecond science: recent highlights and future trends, Annu. Rev. Phys. Chem. 63 (2012) 447-469.

[60] T. Cordes, S.A. Blum, Opportunities and challenges in single-molecule and singleparticle fluorescence microscopy for mechanistic studies of chemical reactions, Nature Chemistry 5 (2013) 993-999.

[61] S.A. Blum, Location change method for imaging chemical reactivity and catalysis with single-molecule and -particle fluorescence microscopy, Phys. Chem. Chem. Phys. 16 (2014) 16333-16339.

[62] P.C. Hohenberg, W. Kohn, Inhomogeneous electron gas, Phys. Rev. 136 (1964) B864-B871.

[63] A. Martin Pendas, E. Francisco, A. Costales, Perspectives for quantum chemical topology in crystallography, Phys. Scripta 87 (2013) 048106-048112. 
[64] P.G. Mezey, The holographic electron density theorem and quantum similarity measures, Mol. Phys. 96 (1999) 169-178.

[65] P. Geerlings, F. De Proft, W. Langenaeker, Conceptual density functional theory, Chem. Rev. 103 (2003) 1793-1873.

[66] R.F.W. Bader, Atoms in molecules: a quantum theory, Oxford University Press, Oxford, 1990.

[67] T.S. Koritsanszky, P. Coppens, Chemical applications of X-ray charge-density analysis, Chem. Rev., 101 (2001) 1583-1628.

[68] P. Nasertayoob, S. Shahbazian, The topological analysis of electronic charge densities: A reassessment of foundations, J. Mol. Struct.- Theochem 869 (2008) 53-58.

[69] K. Collard, G.G. Hall, Orthogonal trajectories of the electron density, Int. J. Quantum Chem. 12 (1977) 623-637.

[70] C. K. Johnson, In American Crystallography Association Winter Meeting at Asilomar Communicated abstracts, Asilomar, Winter, 1977

[71] V.H. Smith, P.F. Price, I. Absar, Representations of electron-density and its topographical features, Isr. J. Chem. 16 (1977) 187-197.

[72] R.F.W. Bader, S.G. Anderson, A.J. Duke, Quantum topology of molecular chargedistributions .1, J. Am. Chem. Soc. 101 (1979) 1389-1395.

[73] R.F.W. Bader, T.T. Nguyendang, Y. Tal, Quantum topology of molecular chargedistributions .2. Molecular structure and its change, J. Chem. Phys. 70 (1979) 43164329.

[74] Y. Tal, R.F.W. Bader, T.T. Nguyendang, M. Ojha, S.G. Anderson, Quantum topology .4. Relation between the topological and energetic stabilities of molecularstructures, J. Chem. Phys. 74 (1981) 5162-5167.

[75] R.F.W. Bader, Y. Tal, S.G. Anderson, T.T. Nguyen-Dang, Quantum topology. Theory of molecular-structure and its change, Isr. J. Chem., 19 (1980) 8.

[76] T.T. Nguyen-Dang, R.F.W. Bader, A theory of molecular structure, Physica A: statistical mechanics and its applications, 114 (1982) 68-73.

[77] R.F.W. Bader, T.T. Nguyen-Dang, Y. Tal, A topological theory of molecular structure, Rep. Prog. Phys. 44 (1981) 893.

[78] R.F.W. Bader, A quantum theory of molecular structure and its applications, Chem. Rev. 91 (1991) 893-928.

[79] R.F.W. Bader, Principle of stationary action and the definition of a proper open system, Phys. Rev. B 49 (1994) 13348-13356.

[80] C.F. Matta, R.J. Boyd, An Introduction to the quantum theory of atoms in molecules. The quantum theory of atoms in molecules, Wiley-VCH Verlag $\mathrm{GmbH} \&$ Co. KGaA2007, pp. 1-34.

[81] C. Gatti, Challenging chemical concepts through charge density of molecules and crystals, Phys. Scripta 87 (2013) 048102.

[82] G.R. Runtz, R.F.W. Bader, R.R. Messer, Definition of bond paths and bond directions in terms of molecular charge distribution, Can. J. Chem. 55 (1977) 30403045.

[83] D. Chopra, Advances in understanding of chemical bonding: inputs from experimental and theoretical charge density analysis, J. Phys. Chem. A 116 (2012) 9791-9801.

[84] A. Otero-de-la-Roza, V. Luana, Topological characterization of the electron density laplacian in crystals. The case of the group IV elements, J. Chem. Theory Comput. 6 (2010) 3761-3779. 
[85] A. Otero-de-la-Roza, E.R. Johnson, V. Luana, CRITIC2: A program for real-space analysis of quantum chemical interactions in solids, Comput. Phys. Commun. 185 (2014) 1007-1018.

[86] M. Goli, S. Shahbazian, The two-component quantum theory of atoms in molecules (TC-QTAIM): the unified theory of localization/delocalization of electrons, nuclei, and exotic elementary particles, Theor. Chem. Acc. 132 (2013).

[87] M. Goli, S. Shahbazian, Toward the multi-component quantum theory of atoms in molecules: a variational derivation, Theor. Chem. Acc. 132 (2013) 1-17.

[88] M. Goli, S. Shahbazian, The two-component quantum theory of atoms in molecules (TC-QTAIM): tensor formulation and its implications, Theor. Chem. Acc. 132 (2013) 1-14.

[89] D. Ferro-Costas, A.M. Pendas, L. Gonzalez, R.A. Mosquera, Beyond the molecular orbital conception of electronically excited states through the quantum theory of atoms in molecules, Phys. chem. chem. phys. 16 (2014) 9249-9258.

[90] A.D. Becke, K.E. Edgecombe, A simple measure of electron localization in atomic and molecular systems, J. Chem. Phys. 92 (1990) 5397-5403.

[91] A. Savin, R. Nesper, S. Wengert, T.F. Fässler, ELF: The electron localization function, Angew. Chem. Int. Ed. 36 (1997) 1808-1832.

[92] B. Silvi, The spin-pair compositions as local indicators of the nature of the bonding, J. Phys. Chem. A 107 (2003) 3081-3085.

[93] E. Matito, B. Silvi, M. Duran, M. Sola, Electron localization function at the correlated level, J. Chem. Phys. 125 (2006).

[94] A. Savin, O. Jepsen, J. Flad, O.K. Andersen, H. Preuss, H.G.v. Schnering, Electron localization in solid-state structures of the elements: the diamond structure, Angew. Chem. Int. Ed. 31 (1992) 187-188.

[95] C.F. Von Weizsacker, Theory of nuclear masses, Z. Phys. 96 (1935) 431-458.

[96] L.H. Thomas, Calculation of atomic fields, P. Camb. Philos. Soc. 33 (1927) 542548.

[97] E. Fermi, Statistical method of investigating electrons in atoms, Z. Phys. 48 (1928) 73-79.

[98] C. Gatti, Solid state applications of QTAIM and the source functions molecular crystals, surfaces, host-guest systems and molecular complexes, in: R.J. Boyd, C.F. Matta (Eds.) The Quantum Theory of Atoms in Molecules: From Solid State to DNA and Drug Design, Wiley-VCH, Weinheim, 2007, pp. 165-206.

[99] A.M. Simas, V.H. Smith Jr., A.J. Thakkar, Partial-wave analysis of the momentum densities of 14 electron diatomics, Int. J. Quantum Chem. 26 (1984) 385-392.

[100] R.F.W. Bader, G.L. Heard, The mapping of the conditional pair density onto the electron density, J. Chem. Phys. 111 (1999) 8789-8798.

[101] Y. Tal, R.F.W. Bader, J. Erkku, Structural homeomorphism between the electronic charge density and the nuclear potential of a molecular system, Phys. Rev. A 21 (1980) 1-11.

[102] T.A. Keith, R.F.W. Bader, Y. Aray, Structural homeomorphism between the electron density and the virial field, Int. J. Quantum Chem. 57 (1996) 183-198.

[103] F. Cortés-Guzmán, R.F.W. Bader, Complementarity of QTAIM and MO theory in the study of bonding in donor-acceptor complexes, Coord. Chem. Rev. 249 (2005) 633662.

[104] R.F.W. Bader, R.J. Gillespie, P.J. MacDougall, A physical basis for the VSEPR model of molecular geometry, J. Am. Chem. Soc. 110 (1988) 7329-7336. 
[105] R.F.W. Bader, P.J. MacDougall, C.D.H. Lau, Bonded and nonbonded charge concentrations and their relation to molecular geometry and reactivity, J. Am. Chem. Soc. 106 (1984) 1594-1605.

[106] M. Kohout, A measure of electron localizability, Int. J. Quantum Chem. 97 (2004) 651-658.

[107] P. de Silva, C. Corminboeuf, Simultaneous visualization of covalent and noncovalent interactions using regions of density overlap, J. Chem. Theory Comput. (2014) DOI: $10.1021 / \mathrm{ct} 500490 \mathrm{~b}$.

[108] P. Balanarayan, R. Kavathekar, S.R. Gadre, Electrostatic potential topography for exploring electronic reorganizations in 1,3 dipolar cycloadditions, J. Phys. Chem. A 111 (2007) 2733-2738.

[109] P.G. Mezey, Catchment region partitioning of energy hypersurfaces, I, Theor. Chim. Acta, 58 (1981) 309-330.

[110] P.G. Mezey, Potential energy hypersurfaces, Elsevier, Amsterdam, 1987.

[111] P. Pyykko, Strong closed-shell interactions in inorganic chemistry, Chem. Rev. 97 (1997) 597-636.

[112] S. Grimme, Density functional theory with London dispersion corrections, Wiley Interdisciplinary Reviews-Computational Molecular Science, 1 (2011) 211-228.

[113] S. Grimme, J. Antony, T. Schwabe, C. Mueck-Lichtenfeld, Density functional theory with dispersion corrections for supramolecular structures, aggregates, and complexes of (bio)organic molecules, Org. Biomol. Chem. 5 (2007) 741-758.

[114] K.E. Riley, P. Hobza, Noncovalent interactions in biochemistry, Wiley Interdisciplinary Reviews-Computational Molecular Science, 1 (2011) 3-17.

[115] K.S. Kim, P. Tarakeshwar, J.Y. Lee, Molecular clusters of pi-systems: Theoretical studies of structures, spectra, and origin of interaction energies, Chem. Rev. 100 (2000) 4145-4185.

[116] G.R. Desiraju, Crystal engineering: A holistic view, Angew. Chem. Int. Edit. 46 (2007) 8342-8356.

[117] K. Muller-Dethlefs, P. Hobza, Noncovalent interactions: a challenge for experiment and theory, Chem. Rev. 100 (2000) 143-167.

[118] W. Tang, S. Johnston, J.A. Iggo, N.G. Berry, M. Phelan, L. Lian, J. Bacsa, J. Xiao, Cooperative catalysis through noncovalent interactions, Angew. Chem. Int. Edit. 52 (2013) 1668-1672.

[119] R. Chaudret, B. de Courcy, J. Contreras-Garcia, E. Gloaguen, A. ZehnackerRentien, M. Mons, J.P. Piquemal, Unraveling non-covalent interactions within flexible biomolecules: from electron density topology to gas phase spectroscopy, Phys. Chem. Chem. Phys. 16 (2014) 9876-9891.

[120] A.J. Cohen, P. Mori-Sanchez, W. Yang, Insights into current limitations of density functional theory, Science 321 (2008) 792-794.

[121] E.R. Johnson, S. Keinan, P. Mori-Sánchez, J. Contreras-García, A.J. Cohen, W. Yang, Revealing noncovalent interactions, J. Am. Chem. Soc. 132 (2010) 6498-6506.

[122] J. Contreras-García, E.R. Johnson, S. Keinan, R. Chaudret, J.-P. Piquemal, D.N. Beratan, W. Yang, NCIPLOT: A Program for plotting noncovalent interaction regions, J. Chem. Theor. Comput. 7 (2011) 625-632.

[123] N. Gillet, R. Chaudret, J. Contreras-García, W. Yang, B. Silvi, J.-P. Piquemal, Coupling quantum interpretative techniques: another look at chemical mechanisms in organic reactions, J. Chem. Theor. Comput. 8 (2012) 3993-3997.

[124] D. Fang, R. Chaudret, J.-P. Piquemal, G.A. Cisneros, Toward a deeper understanding of enzyme reactions using the coupled ELF/NCI analysis: application to dna repair enzymes, J. Chem. Theory Comput. 9 (2013) 2156-2160. 
[125] J. Andres, S. Berski, J. Contreras-Garcia, P. Gonzalez-Navarrete, Following the molecular mechanism for the $\mathrm{NH}_{3}+\mathrm{LiH} \rightarrow \mathrm{LiNH}_{2}+\mathrm{H}_{2}$ chemical reaction: a study based on the joint use of the quantum theory of atoms in molecules (QTAIM) and noncovalent interaction (NCI) index, J. Phys. Chem. A 118 (2014) 1663-1672.

[126] A. Otero-de-la-Roza, E.R. Johnson, J. Contreras-Garcia, Revealing non-covalent interactions in solids: NCI plots revisited, Phys. Chem. Chem. Phys. 14 (2012) 1216512172.

[127] G. Saleh, C. Gatti, L. Lo Presti, J. Contreras-Garcia, revealing non-covalent interactions in molecular crystals through their experimental electron densities, ChemEur. J. 18 (2012) 15523-15536.

[128] D. Fang, R.L. Lord, G.A. Cisneros, Ab initio QM/MM calculations show an intersystem crossing in the hydrogen abstraction step in dealkylation catalyzed by AlkB, J. Phys. Chem. B 117 (2013) 6410-6420.

[129] P.L.A. Popelier, Quantum Chemical Topology: on bonds and potentials, in: D.J. Wales (Ed.) Structure and bonding: Intermolecular forces and clusters I, Springer, Heidelberg, 2005.

[130] P.L.A. Popelier, E.A.G. Bremond, Geometrically faithful homeomorphisms between the electron density and the bare nuclear potential, Int. J. Quantum Chem. 109 (2009) 2542-2553.

[131] B. de Courcy, L.G. Pedersen, O. Parisel, N. Gresh, B. Silvi, J. Pilme, J.P. Piquemal, Understanding selectivity of hard and soft metal cations within biological systems using the subvalence concept. 1. Application to blood coagulation: direct cation-protein electronic effects versus indirect interactions through water networks, J. Chem. Theory Comput. 6 (2010) 1048-1063.

[132] J. Pilme, H. Berthoumieux, V. Robert, P. Fleurat-Lessard, Unusual bond formation in aspartic protease inhibitors: A theoretical study, Chem-Eur. J. 13 (2007) 5388-5393.

[133] A. de la Lande, J. Maddaluno, O. Parisel, T.A. Darden, J.P. Piquemal, Study of the docking of competitive inhibitors at a model of tyrosinase active site: insights from joint broken-symmetry/spin-flip dft computations and ELF topological analysis, Interdiscip. Sci. 2 (2010) 3-11.

[134] S. Berski, J. Andrés, B. Silvi, L.R. Domingo, New findings on the diels-alder reactions. an analysis based on the bonding evolution theory, J. Phys. Chem. A, 110 (2006) 13939-13947.

[135] J. Poater, M. Duran, M. Sola, B. Silvi, Theoretical evaluation of electron delocalization in aromatic molecules by means of atoms in molecules (AIM) and electron localization function (ELF) topological approaches, Chem. Rev. 105 (2005) 3911-3947.

[136] F. Pauzat, J. Pilme, J. Toulouse, Y. Ellinger, About the collapse of the 3.3 microm $\mathrm{CH}$ stretching band with ionization in polycyclic aromatic hydrocarbons: configuration interaction and quantum Monte Carlo studies of the $\mathrm{CH}$ fragment, J. Chem. Phys. 133 (2010).

[137] P. Rivera-Fuentes, J.L. Aonso-Gomez, A.G. Petrovic, P. Seiler, F. Santoro, N. Harada, N. Berova, H.S. Rzepa, F. Diederich, Enantiomerically pure alleno-acetylenic macrocycles: synthesis, solid-state structures, chiroptical properties, and electron localization function analysis, Chem-Eur. J. 16 (2010) 9796-9807.

[138] J. Berges, I. Fourre, J. Pilme, J. Kozelka, Quantum chemical topology study of the water-platinum(II) interaction, Inorg. Chem. 52 (2013) 1217-1227.

[139] B. Silvi, A. Savin, Classification of chemical bonds based on topological analysis of electron localization functions, Nature 371 (1994) 683-686. 
[140] A. Savin, B. Silvi, F. Colonna, Topological analysis of the electron localization function applied to delocalized bonds, Can. J. Chem. 74 (1996) 1088-1096.

[141] S. Raub, G. Jansen, A quantitative measure of bond polarity from the electron localization function and the theory of atoms in molecules, Theor. Chem. Acc. 106 (2001) 223-232.

[142] R. Llusar, A. Beltran, J. Andres, F. Fuster, B. Silvi, Topological analysis of multiple metal-metal bonds in dimers of the M-2(formamidinate)(4) type with $\mathrm{M}=\mathrm{Nb}$, Mo, Tc, Ru, Rh, and Pd, J. Phys. Chem. A 105 (2001) 9460-9466.

[143] B. Silvi, The synaptic order: a key concept to understand multicenter bonding, J. Mol. Struct. 614 (2002) 3-10.

[144] J. Pilme, B. Silvi, M.E. Alikhani, Structure and stability of M-CO, M equals firsttransition-row metal: An application of density functional theory and topological approaches, J. Phys. Chem. A 107 (2003) 4506-4514.

[145] E. Matito, M. Sola, The role of electronic delocalization in transition metal complexes from the electron localization function and the quantum theory of atoms in molecules viewpoints, Coordin. Chem. Rev. 253 (2009) 647-665.

[146] Y. Aray, J. Rodriguez, D. Vega, Topology of the electron density and cohesive energy of the face-centered cubic transition metals, J. Phys. Chem. B 104 (2000) 46084612.

[147] G. Gervasio, R. Bianchi, D. Marabello, About the topological classification of the metal-metal bond, Chem. Phys. Lett. 387 (2004) 481-484.

[148] J. Reinhold, O. Kluge, C. Mealli, Integration of electron density and molecular orbital techniques to reveal questionable bonds: the test case of the direct $\mathrm{Fe}-\mathrm{Fe}$ bond in Fe-2(CO)(9), Inorg. Chem. 46 (2007) 7142-7147.

[149] E. Espinosa, I. Alkorta, J. Elguero, E. Molins, From weak to strong interactions: a comprehensive analysis of the topological and energetic properties of the electron density distribution involving X-H center dot center dot center dot F-Y systems, J. Chem. Phys. 117 (2002) 5529-5542.

[150] B. Silvi, Importance of electrostatic interactions between nonbonded molecules in ice, Phys. Rev. Lett. 73 (1994) 842-845.

[151] R.A. Cormanich, R.T. Santiago, F.A. La Porta, M.P. Freitas, R. Rittner, E.F.F. da Cunha, J. Andres, E. Longo, T.C. Ramalho, Quantum chemical topological analysis of hydrogen bonding in $\mathrm{HX}$...HX and $\mathrm{CH}_{3} \mathrm{X}$...HX dimers $(\mathrm{X}=\mathrm{Br}, \mathrm{Cl}, \mathrm{F})$, Molecular Simulation, (2014) 1-10.

[152] R. Thom, Catastrophe theory, Nature 270 (1977) 658.

[153] X. Krokidis, S. Noury, B. Silvi, Characterization of elementary chemical processes by catastrophe theory, J. Phys. Chem. A, 101 (1997) 7277-7282.

[154] X. Krokidis, R. Vuilleumier, D. Borgis, B. Silvi, A topological analysis of the proton transfer in $\mathrm{H}_{5} \mathrm{O}^{+2}$, Mol. Phys. 96 (1999) 265-273.

[155] V. Polo, J. Andres, S. Berskit, L.R. Domingo, B. Silvi, Understanding reaction mechanisms in organic chemistry from catastrophe theory applied to the electron localization function topology, J. Phys. Chem. A 112 (2008) 7128-7136.

[156] P. González-Navarrete, L.R. Domingo, J. Andrés, S. Berski, B. Silvi, Electronic fluxes during diels-alder reactions involving 1,2-benzoquinones: mechanistic insights from the analysis of electron localization function and catastrophe theory, J. Comput. Chem. 33 (2012) 2400-2411.

[157] J. Andres, S. Berski, L.R. Domingo, P. Gonzalez-Navarrete, Nature of the ringclosure process along the rearrangement of octa-1,3,5,7-tetraene to cycloocta-1,3,5triene from the perspective of the electron localization function and catastrophe theory, J. Comput. Chem. 33 (2012) 748-756. 
[158] J. Andres, S. Berski, L.R. Domingo, V. Polo, B. Silvi, Describing the molecular mechanism of organic reactions by using topological analysis of electronic localization function, Curr. Org. Chem. 15 (2011) 3566-3575.

[159] J.C. Santos, J. Andres, A. Aizman, P. Fuentealba, V. Polo, A theoretical study on the reaction mechanism for the Bergman cyclization from the perspective of the electron localization function and catastrophe theory, J. Phys. Chem. A 109 (2005) 3687-3693. [160] J. Kalinowski, S. Berski, A.J. Gordon, Electron localization function study on intramolecular electron transfer in the QTTFQ and DBTTFI radical anions, J. Phys. Chem. A 115 (2011) 13513-13522.

[161] V. Polo, P. Gonzalez-Navarrete, B. Silvi, J. Andres, An electron localization function and catastrophe theory analysis on the molecular mechanism of gas-phase identity S(N)2 reactions, Theor. Chem. Acc. 120 (2008) 341-349.

[162] S. Chiodo, O. Kondakova, M.D. Michelini, N. Russo, E. Sicilia, Reaction of bare $\mathrm{VO}+$ and $\mathrm{FeO}+$ with ammonia: A theoretical point of view, Inorg. Chem. 42 (2003) 8773-8782.

[163] M.D. Michelini, E. Sicilia, N. Russo, M.E. Alikhani, B. Silvi, Topological analysis of the reaction of $\mathrm{Mn}+(\mathrm{S}-7, \mathrm{~S}-5)$ with $\mathrm{H}_{2} \mathrm{O}, \mathrm{NH}_{3}$, and $\mathrm{CH}_{4}$ molecules, J. Phys. Chem. A 107 (2003) 4862-4868.

[164] S. Chiodo, O. Kondakova, M.D. Michelini, N. Russo, E. Sicilia, A. Irigoras, J.M. Ugalde, Theoretical study of two-state reactivity of transition metal cations: the "difficult" case of iron ion interacting with water, ammonia, and methane, J. Phys. Chem. A 108 (2004) 1069-1081.

[165] M.E. Alikhani, M.D. Michelini, N. Russo, B. Silvi, Topological analysis of the reaction of uranium ions $\left(\mathrm{U}^{+}, \mathrm{U}^{2+}\right)$ with $\mathrm{N}_{2} \mathrm{O}$ in the Gas Phase, J. Phys. Chem. A 112 (2008) 12966-12974.

[166] S. Berski, F.R. Sensato, V. Polo, J. Andres, V.S. Safont, Olefin epoxidation by molybdenum peroxo compound: molecular mechanism characterized by the electron localization function and catastrophe theory, J. Phys. Chem. A 115 (2011) 514-522.

[167] P. Gonzalez-Navarrete, F. Sensato, J. Andrés, E. Longo, Oxygen atom transfer reactions from mimoun complexes to sulfides and sulfoxides. a bonding evolution theory analysis, J. Phys. Chem. A (2014) 10.1021/jp504172g.

[168] A. Morales-Bayuelo, Understanding the electronic reorganization in the thermal isomerization reaction of trans-3,4-dimethylcyclobutene. Origins of outward pseudodiradical $\{2 n+2\}$ torquoselectivity, Int. J. Quantum Chem. 113 (2013) 15341543.

[169] A.S. Nizovtsev, Activation of C-H bond in methane by Pd atom from the bonding evolution theory perspective, J. Phys. Chem. A 34 (2013) 1917-1924.

[170] A.S. Nizovtsev, S.G. Kozlova, Electronic rearrangements during the inversion of lead phthalocyanine, J. Phys. Chem. A 117 (2013) 481-488.

[171] J. Andrés, P. González-Navarrete, V.S. Safont, Unraveling reaction mechanisms by means of Quantum Chemical Topology Analysis, Int. J. Quantum Chem. (2014) 10.1002/qua.24665

[172] P. González-Navarrete, J. Andrés, S. Berski, How a quantum chemical topology analysis enables prediction of electron density transfers in chemical reactions. The degenerated cope rearrangement of semibullvalene, J. Phys. Chem. Lett. 3 (2012) 25002505.

[173] T. Bredtmann, J. Manz, Electronic bond-to-bond fluxes in pericyclic reactions: synchronous or asynchronous?, Angew. Chem. Int. Edit. 50 (2011) 12652-12654.

[174] T. Bredtmann, J. Manz, Optimal control of the initiation of a pericyclic reaction in the electronic ground state, J. Chem. Sci. 124 (2012) 121-129. 
[175] L.R. Domingo, P. Perez, J.A. Saez, Understanding C-C bond formation in polar reactions. An ELF analysis of the friedel-crafts reaction between indoles and nitroolefins, RCS Adv. 3 (2013) 7520-7528.

[176] L.R. Domingo, M.J. Aurell, P. Perez, The mechanism of ionic diels-alder reactions. A DFT study of the oxa-Povarov reaction, RCS Adv. 4 (2014) 16567-16577.

[177] L.R. Domingo, P. Perez, J.A. Saez, Understanding the regioselectivity in hetero diels-alder reactions. An ELF analysis of the reaction between nitrosoethylene and 1vinylpyrrolidine, Tetrahedron, 69 (2013) 107-114.

[178] L.R. Domingo, J.A. Saez, J.A. Joule, L. Rhyman, P. Ramasami, A DFT study of the $3+2$ versus $4+2$ cycloaddition reactions of 1,5,6-trimethylpyrazinium-3-olate with methyl methacrylate, J. Org. Chem. 78 (2013) 1621-1629.

[179] L.R. Domingo, A New C-C Bond Formation Model Based on the Quantum Chemical Topology of Electron Density, RCS Adv. (2014) DOI: 10.1039/C4RA04280H.

[180] L.R. Domingo, P. Perez, A quantum chemical topological analysis of the C-C bond formation in organic reactions involving cationic species, Phys. Chem. Chem. Phys. 16 (2014) 14108-14115.

[181] H. Gerard, I. Chataigner, Selectivities of multicomponent 4+2 / 3+2 cycloadditions of 3-nitroindole with substituted alkenes: a DFT analysis, J. Org. Chem. 78 (2013) 9233-9242.

[182] A. Sanchez-Gonzalez, S. Melchor, J.A. Dobado, B. Silvi, J. Andres, N, P, and As ylides and aza- and arsa-wittig reactions from topological analyses of electron density, J. Phys. Chem. A 115 (2011) 8316-8326.

[183] M.M. Vallejos, N. Grimblat, S.C. Pellegrinet, Reactivity and selectivity of boronsubstituted alkenes in the diels-alder reaction with cyclopentadiene. A study of the electron charge density and its laplacian, J. Phys. Chem. A (2014).

[184] V. Luana, A. Costales, A.M. Pendas, Ions in crystals: the topology of the electron density in ionic materials .2. The cubic alkali halide perovskites, Phys. Rew. B 55 (1997) 4285-4297.

[185] A.M. Pendas, A. Costales, V. Luana, Ions in crystals: the topology of the electron density in ionic materials .1. fundamentals, Phys. Rew. B 55 (1997) 4275-4284.

[186] A.M. Pendas, A. Costales, V. Luana, Ions in crystals: The topology of the electron density in ionic materials. III. Geometry and ionic radii, J. Phys. Chem. B 102 (1998) 6937-6948.

[187] G.V. Gibbs, K.M. Rosso, D.M. Teter, M.B. Boisen, M.S.T. Bukowinski, Model structures and properties of the electron density distribution for low quartz at pressure: a study of the SiO bond, J. Mol. Struct. 485 (1999) 13-25.

[188] G.V. Gibbs, M.B. Boisen, K.M. Rosso, D.M. Teter, M.S.T. Bukowinski, Model structures and electron density distributions for the silica polymorph coesite at pressure: an assessment of O O bonded interactions, J. Phys. Chem. B 104 (2000) 10534-10542.

[189] G.V. Gibbs, A.E. Whitten, M.A. Spackman, M. Stimpfl, R.T. Downs, M.D. Carducci, An exploration of theoretical and experimental electron density distributions and $\mathrm{SiO}$ bonded interactions for the silica polymorph coesite, J. Phys. Chem. B 107 (2003) 12996-13006.

[190] J.S. Tse, in: C. Gatti, P. Macchi (Eds.) Modern Charge-density Analysis, Springer Verlag, New York, 2012.

[191] J.S. Tse, Crystallography of selected high pressure elemental solids, Z. Kristallogr. 220 (2005) 521-530.

[192] J. Contreras-García, M. Marqués, B. Silvi, J. Recio, Bonding Changes Along Solid-Solid Phase Transitions Using the Electron Localization Function Approach, in: 
C. Gatti, P. Macchi (Eds.) Modern Charge-Density Analysis, Springer Netherlands 2012, pp. 625-658.

[193] M.A. Salvado, P. Pertierra, A. Morales-Garcia, J.M. Menendez, J.M. Recio, Understanding chemical changes across the alpha-cristobalite to stishovite transition path in silica, J. Phys. Chem. C 117 (2013) 8950-8958.

[194] M. Prencipe, F. Nestola, Quantum-mechanical modeling of minerals at high pressures. The role of the Hamiltonian in a case study: the beryl (Al4Be6Si12O36), Phys. Chem. Miner. 32 (2005) 471-479.

[195] M. Merli, F. Nestola, L. Sciascia, Bader's analysis of the electron density in the Pbca enstatite - Pbcn protoenstatite phase transition, Eur. J. Mineral 23 (2011) 197-205. [196] F. Parisi, L. Sciascia, F. Princivalle, M. Merli, The pressure-induced ringwoodite to Mg-perovskite and periclase post-spinel phase transition: a Bader's topological analysis of the ab initio electron densities, Phys. Chem. Miner. 39 (2012) 103-113.

[197] M. Merli, L. Sciascia, Bader's topological analysis of the electron density in the pressure-induced phase transitions/amorphization in alpha-quartz from the catastrophe theory viewpoint, Phys. Chem. Miner. 40 (2013) 455-466.

[198] A. Vegas, R. Notario, E. Chamorro, P. Perez, J.F. Liebman, Isoelectronic and isolobal $\mathrm{O}, \mathrm{CH}_{2}, \mathrm{CH}_{3}{ }^{+}$and $\mathrm{BH}_{3}$ as electron pairs; similarities between molecular and solid-state chemistry, Acta Crystallogr. B 69 (2013) 163-175.

[199] M.R. Ryzhikov, V.A. Slepkov, S.G. Kozlova, S.P. Gabuda, Evolution of chemical bonding and electron density rearrangements during D3h $\rightarrow$ D3d reaction in monolayered TiS2: a QTAIM and ELF study, J. Comput. Chem. (2014) DOI: $10.1002 /$ jcc. 23662.

[200] E. Longo, L.S. Cavalcante, D.P. Volanti, A.F. Gouveia, V.M. Longo, J.A. Varela, M.O. Orlandi, J. Andres, Direct in situ observation of the electron-driven synthesis of Ag filaments on alpha-Ag2WO4 crystals, Sci. Rep. 3 (2013).

[201] E. Longo, D.P. Volanti, V.M. Longo, L. Gracia, I.C. Nogueira, M.A.P. Almeida, A.N. Pinheiro, M.M. Ferrer, L.S. Cavalcante, J. Andres, Toward an understanding of the growth of ag filaments on alpha-Ag2WO4 and their photoluminescent properties: a combined experimental and theoretical study, J. Phys. Chem. C 118 (2014) 1229-1239.

[202] V.M. Longo, C.C. De Foggi, M.M. Ferrer, A.F. Gouveia, R.S. André, W. Avansi, C.E. Vergani, A.L. Machado, J. Andrés, L.S. Cavalcante, A.C. Hernandes, E. Longo, Potentiated electron transference in $\alpha-\mathrm{Ag}_{2} \mathrm{WO}_{4}$ microcrystals with $\mathrm{Ag}$ nanofilaments as microbial agent, J. Phys. Chem. A (2014) DOI: 10.1021/jp410564p.

[203] J. Andres, L. Gracia, P. Gonzalez-Navarrete, V.M. Longo, W. Avansi, Jr., D.P. Volanti, M.M. Ferrer, P.S. Lemos, F.A. La Porta, A.C. Hernandes, E. Longo, Structural and electronic analysis of the atomic scale nucleation of $\mathrm{Ag}$ on alpha- $\mathrm{Ag}_{2} \mathrm{WO}_{4}$ induced by electron irradiation, Sci. Rep. 4 (2014) 5391-5391.

[204] G. Kresse, J. Hafner, Ab-Initio molecular-dynamics simulation of the liquid-metal amorphous-semiconductor transition in germanium, Phys. Rew. B 49 (1994) 1425114269.

[205] G. Kresse, J. Furthmuller, Efficiency of ab-initio total energy calculations for metals and semiconductors using a plane-wave basis set, Comp. Mater. Sci. 6 (1996) $15-50$.

[206] J.P. Perdew, K. Burke, M. Ernzerhof, Generalized gradient approximation made simple, Phys. Rew. Lett. 77 (1996) 3865-3868.

[207] G. Kresse, D. Joubert, From ultrasoft pseudopotentials to the projector augmented-wave method, Phys. Rew. B 59 (1999) 1758-1775. 
[208] S.L. Dudarev, G.A. Botton, S.Y. Savrasov, C.J. Humphreys, A.P. Sutton, Electron-energy-loss spectra and the structural stability of nickel oxide: An LSDA+U study, Phys. Rew. B 57 (1998) 1505-1509.

[209] K. Exner, P.V. Schleyer, Planar hexacoordinate carbon: a viable possibility, Science 290 (2000) 1937-1940.

[210] Z.X. Wang, P.V. Schleyer, Construction principles of "hyparenes": Families of molecules with planar pentacoordinate carbons, Science 292 (2001) 2465-2469.

[211] S.D. Li, C.Q. Miao, G.M. Ren, D-5h $\mathrm{Cu}_{5} \mathrm{H}_{5} \mathrm{X}$ : Pentagonal hydrocopper $\mathrm{Cu}_{5} \mathrm{H}_{5}$ containing pentacoordinate planar nonmetal Centers $(\mathrm{X}=\mathrm{B}, \mathrm{C}, \mathrm{N}, \mathrm{O})$, Eur. J. Inorg. Chem. (2004) 2232-2234.

[212] K. Ito, Z. Chen, C. Corminboeuf, C.S. Wannere, X.H. Zhang, Q.S. Li, P.v.R. Schleyer, Myriad planar hexacoordinate carbon molecules inviting synthesis, J. Am. Chem. Soc. 129 (2007) 1510-1511.

[213] L.-M. Wang, W. Huang, B.B. Averkiev, A.I. Boldyrev, L.-S. Wang, CB7-: Experimental and theoretical evidence against hypercoordinate planar carbon, Angew. Chem. Int. Edit. 46 (2007) 4550-4553.

[214] B.B. Averkiev, D.Y. Zubarev, L.-M. Wang, W. Huang, L.-S. Wang, A.I. Boldyrev, Carbon avoids hypercoordination in $\mathrm{CB}_{6}^{-}, \mathrm{CB}_{6}^{2-}$, and $\mathrm{C}_{2} \mathrm{~B}_{5}^{-}$planar carbonboron clusters, J. Am. Chem. Soc. 130 (2008) 9248-+.

[215] Y.-B. Wu, Z.-X. Li, X.-H. Pu, Z.-X. Wang, Computational design of linear, flat, and tubular nanomolecules using planar tetracoordinate carbon $\mathrm{C}_{2} \mathrm{Al}_{4}$ units, Comput. Theor. Chem. 992 (2012) 78-83.

[216] Z.-h. Cui, M. Contreras, Y.-h. Ding, G. Merino, Planar tetracoordinate carbon versus planar tetracoordinate boron: the case of $\mathrm{CB}_{4}$ and its cation, J. Am. Chem. Soc. 133 (2011) 13228-13231.

[217] Y.-B. Wu, Y. Duan, G. Lu, H.-G. Lu, P. Yang, P.v.R. Schleyer, G. Merino, R. Islas, Z.-X. Wang, $\mathrm{D}_{3 \mathrm{~h}} \mathrm{CN}_{3} \mathrm{Be}_{3}{ }^{+}$and $\mathrm{CO}_{3} \mathrm{Li}_{3}{ }^{+}$: viable planar hexacoordinate carbon prototypes, Phys. Chem. Chem. Phys. 14 (2012) 14760-14763.

[218] Y.-B. Wu, Y. Duan, H.-G. Lu, S.-D. Li, $\mathrm{CAl}_{2} \mathrm{Be}_{3}{ }^{2-}$ and its salt complex $\mathrm{LiCAl}_{2} \mathrm{Be}_{3}{ }^{-}$: anionic global minima with planar pentacoordinate carbon, J. Phys. Chem. A 116 (2012) 3290-3294.

[219] C.-F. Zhang, S.-J. Han, Y.-B. Wu, H.-G. Lu, G. Lu, Thermodynamic stability versus kinetic stability: is the planar hexacoordinate carbon species $\mathrm{D}_{3 \mathrm{~h}} \mathrm{CN}_{3} \mathrm{Mg}_{3}{ }^{+}$ viable?, J. Phys. Chem. A 118 (2014) 3319-3325.

[220] S. Noury, X. Krokidis, F. Fuster, B. Silvi, Computational tools for the electron localization function topological analysis, Comput. Chem. 23 (1999) 597-604.

[221] K. Fukui, The path of chemical-reactions. The IRC approach, Acc. Chem. Res. 14 (1981) 363-368.

[222] K. Fukui, A formulation of reaction coordinate, J. Phys. Chem. 74 (1970) 41614163.

[223] Gaussian 09, G.W.T. M. J. Frisch, H. B. Schlegel, G. E. Scuseria, , J.R.C. M. A. Robb, G. Scalmani, V. Barone, B. Mennucci, , H.N. G. A. Petersson, M. Caricato, X. Li, H. P. Hratchian, , J.B. A. F. Izmaylov, G. Zheng, J. L. Sonnenberg, M. Hada, , K.T. M. Ehara, R. Fukuda, J. Hasegawa, M. Ishida, T. Nakajima, , O.K. Y. Honda, H. Nakai, T. Vreven, J. A. Montgomery, Jr., , F.O. J. E. Peralta, M. Bearpark, J. J. Heyd, E. Brothers, , V.N.S. K. N. Kudin, T. Keith, R. Kobayashi, J. Normand, , A.R. K. Raghavachari, J. C. Burant, S. S. Iyengar, J. Tomasi, , N.R. M. Cossi, J. M. Millam, M. Klene, J. E. Knox, J. B. Cross, , C.A. V. Bakken, J. Jaramillo, R. Gomperts, R. E. Stratmann, , A.J.A. O. Yazyev, R. Cammi, C. Pomelli, J. W. Ochterski, , K.M. R. L. Martin, V. G. Zakrzewski, G. A. Voth, , J.J.D. P. Salvador, S. Dapprich, A. D. Daniels, , 
J.B.F. O. Farkas, J. V. Ortiz, J. Cioslowski, , G. and D. J. Fox, Inc., Wallingford CT, 2010.

[224] Taken from The Herbert Spencer Lecture, delivered at Oxford University (10 June 1933) (A. Einstein, Philos. Sci., 1934, 1, 163-169)

[225] J. Contreras-Garcia, A. Otero-de-la-Roza, J.M. Recio, An. Quím., 110 (2014) 113-120. 
Graphical abstract 


\section{Highlights}

A quantum chemical topology analysis is reported. ELF and QTAIM have been employed.

We have modeled bonding patterns in solid state and molecules.

We performed the QTAIM analysis on the $\alpha A g 2 \mathrm{WO}_{4}$ for the simulation of $\mathrm{Ag}$ nucleation.

We performed a BET study for the decomposition of the planar carbon species, $\mathrm{CN}_{3} \mathrm{Mg}_{3}{ }^{+}$. 